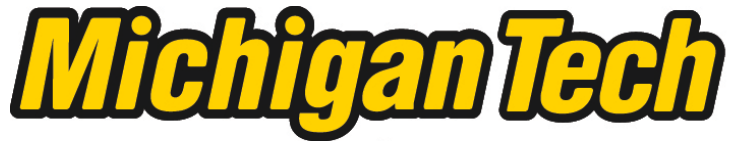 \\ Michigan Technological University Create the Future Digital Commons @ Michigan Tech
}

Dissertations, Master's Theses and Master's Reports - Open

Dissertations, Master's Theses and Master's

Reports

2013

\section{The Planned and the Emergent: An Alternative Model of Learning and Literacy}

Lori S. Rogers

Michigan Technological University

Follow this and additional works at: https://digitalcommons.mtu.edu/etds

Part of the Educational Administration and Supervision Commons, and the Higher Education Commons

Copyright 2013 Lori S. Rogers

\section{Recommended Citation}

Rogers, Lori S., "The Planned and the Emergent: An Alternative Model of Learning and Literacy", Dissertation, Michigan Technological University, 2013.

https://doi.org/10.37099/mtu.dc.etds/683

Follow this and additional works at: https://digitalcommons.mtu.edu/etds

Part of the Educational Administration and Supervision Commons, and the Higher Education Commons 


\title{
THE PLANNED AND THE EMERGENT: AN ALTERNATIVE MODEL OF LEARNING AND LITERACY
}

\author{
By \\ Lori S. Rogers \\ A DISSERTATION \\ Submitted in partial fulfillment of the requirements for the degree of \\ DOCTOR OF PHILOSOPHY \\ In Rhetoric and Technical Communication
}

\section{MICHIGAN TECHNOLOGICAL UNIVERSITY}

2013

Copyright 2013 Lori S. Rogers 

This dissertation has been approved in partial fulfillment of the requirements for the Degree of DOCTOR OF PHILOSOPHY in Rhetoric and Technical Communication.

\section{Department of Humanities}

Dissertation Advisor: Nancy Grimm

Committee Member: Marilyn Cooper

Committee Member: Karla Kitalong

Committee Member: $\quad$ Mari Buche

Department Chair: Ronald Strickland 



\section{Table of Contents}

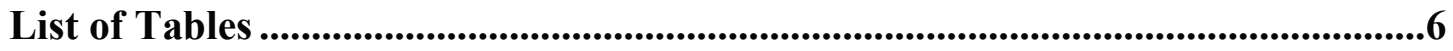

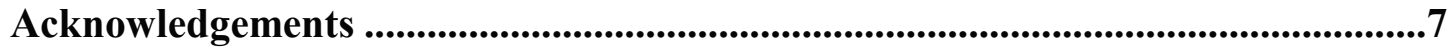

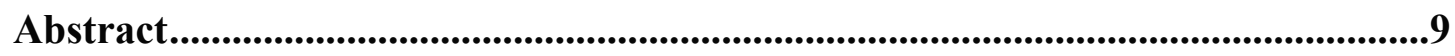

1. Introduction: From Peer Tutoring to Peer Learning .....................................11

2. Enacting a Social Theory of Learning ..................................................................33

3. Negotiating Meaning: Coaches Shaping Learning ......................................59

4. The Work of Belonging: Learning Shaping Coaches .......................................97

5. Conclusion: Supporting the Work of Belonging ..............................................123






\section{List of Tables}

Table 2.1. Types of Questions asked of Students, Coaches and Instructors ...... 57-58 


\section{Acknowledgements}

This dissertation would not be possible without the ongoing support I received from a number of people. I would like to thank my husband, Scott Bellinger, friends and colleagues MaryAnn Crawford and Susan Schiller; RTC Program staff Marjorie Lindley, Kim Puuri, and Gina Dunstan; and Graduate School Assistant Dean, Nancy Byers-Sprague. I want to thank my committee members Marilyn Cooper, Karla Kitalong, and Mari Buche for their valuable feedback and support of this project. Finally, I especially want to thank my Chair, Nancy Grimm, whose inspiration, support, and guidance was the heart that kept this project moving forward. She also helped me keep an important promise to a very special person, and for that, I am forever grateful. 



\begin{abstract}
Within academic institutions, writing centers are uniquely situated, socially rich sites for exploring learning and literacy. I examine the work of the Michigan Tech Writing Center's UN 1002 World Cultures study teams primarily because student participants and Writing Center coaches are actively engaged in structuring their own learning and meaning-making processes. My research reveals that learning is closely linked to identity formation and leading the teams is an important component of the coaches' educational experiences. I argue that supporting this type of learning requires an expanded understanding of literacy and significant changes to how learning environments are conceptualized and developed.

This ethnographic study draws on data collected from recordings and observations of one semester of team sessions, my own experiences as a team coach and UN 1002 teaching assistant, and interviews with Center coaches prior to their graduation. I argue that traditional forms of assessment and analysis emerging from individualized instruction models of learning cannot fully account for the dense configurations of social interactions identified in the Center's program. Instead, I view the Center as an open system and employ social theories of learning and literacy to uncover how the negotiation of meaning in one context influences and is influenced by structures and interactions within as well as beyond its boundaries. I focus on the program design, its enaction in practice, and how engagement in this type of writing center work influences coaches' learning trajectories. I conclude that, viewed as
\end{abstract}


participation in a community of practice, the learning theory informing the program design supports identity formation - a key aspect of learning as argued by Etienne Wenger (1998).

The findings of this study challenge misconceptions of peer learning both in writing centers and higher education that relegate peer tutoring to the role of support for individualized models of learning. Instead, this dissertation calls for consideration of new designs that incorporate peer learning as an integral component. Designing learning contexts that cultivate and support the formation of new identities is complex, involves a flexible and opportunistic design structure, and requires the availability of multiple forms of participation and connections across contexts. 


\section{Chapter 1}

\section{Introduction: From Peer Tutoring to Peer Learning}

Before I began my investigation of the Michigan Tech Writing Center's World Cultures study teams, I believed my work and training in two different writing centers had prepared me well for that cornerstone of writing center pedagogy: the one-to-one session over a piece of written text. Similarly, my graduate level studies in composition and literacy seemed to align well with and helped me to understand what I was noticing as I taught composition courses and worked with individual students in writing centers. When I began coaching and observing the study teams, the ground felt less solid. Initially, the study team sessions I facilitated seemed like a typical discussion group dutifully responding to study guide questions - a recitation session in the Writing Center. I soon began to believe these sessions and the model of learning and literacy emerging from them to be much more than that. I also came to believe that what I observed taking place in the study teams could not be analyzed by the old tools and orthodoxies.

\section{The Problem}

Kenneth Bruffee's 1984 “Collaborative Learning and the Conversation of Mankind" has been and remains a highly influential and often cited model of peer tutoring, but not without criticism (Trimbur 1987, Hobson 1992, Welch 2002, Grimm 2011). I agree with these scholars and others who argue that Bruffee's model presents a limited view of peer tutoring, focusing more on the assimilation of students into a 
particular academic "conversation" and less on the potential contribution of diverse and creative new meanings and practices to the academy. In the 1980s, Bruffee's work as well as Stephen North's (1984) “The Idea of a Writing Center” drew attention to the relatively new concepts of writing centers and peer tutoring - attention that began to define the field of writing center studies. Bruffee (1984) was right in that "there is more to peer tutoring than meets the eye;" however, his model leaves little room to explore the potential of peer tutoring beyond a "romantic idea of the individual as the locus of truth" (Ede, qtd. in Hobson 1992, p.104).

In a similar way, North's (1984) often-quoted axiom that "our job is to produce better writers, not better writing" also places emphasis on an individualistic model of instruction where writers are "changed" through the "process by which [texts] are produced” (“The Idea of a Writing Center,” p. 69). As Nancy Grimm (2011) notes, North's motto, "also promotes a peculiar form of individualized instruction, one that proposes to change the identity of the writer, making him or her "better" (p. 87). Bruffee's (1984) model also seeks to change the writer, thereby implying some fundamental lack. The goal of a peer tutoring session, according to Bruffee (1984), is "normal discourse," which is achieved through conversation. He describes the conversation as,

The tutee brings to the conversation knowledge to written about and knowledge of the assignment. The tutor brings to the conversation knowledge of the conventions of discourse and knowledge of standard written English. If 
the tutee does not bring to the conversation knowledge of the subject and the assignment, the peer tutor's most important contribution is to begin at the beginning: help the tutee acquire the relevant knowledge of the subject and the assignment. What peer tutor and tutee do together is not write or edit, or least of all proofread. What they do together is converse. They converse about the subject and the assignment. They converse about, in an academic context, their own relationship and the relationships between student and teacher. Most of all they converse about and pursuant to writing. (p. 213)

This view of peer tutoring has been highly influential, according to Peter Carino (1995), because it "dissociates tutors from the current-traditional paradigm; they are neither editors nor proofreaders. Second, it exonerates them of suspicions that tutoring borders on the unethical; as peers they work with the student, nor for her. Third, it respects the role of the teacher making the assignment, thus recognizing ... pressures outside the tutorial, and . . . it implies that tutoring gets the business of the university done: academic writing on specified assignments" (p.131).

Bruffee's (1984) description of the peer tutoring process has influenced practice in a number of troubling ways. First, it has led many writing centers to define practice by what they do not do: we don't proofread, we don't write on student's papers, for example. In tutor training handbooks, it has led to an emphasis on prescribed practices: ask the student to read the paper out loud, ask the student if he or she has been to the writing center. While these mantras may provide an entry point 
into a session for new tutors worried about "getting it right," they don't account for or make use of creative new practices to emerge. Perhaps more importantly, views of peer tutoring influenced by models like Bruffee's forever link writing center work as supplemental to the instructional model of the classroom rather than as innovators of important new infrastructures for learning.

What's at stake is the potential to over-look and under-scrutinize the value of peer tutoring. Barnett and Blumer (2001) argue that the "process of tutoring, and how we prepare ourselves and our future tutors to approach this process, is what defines [writing center work] more than any other function we perform” (p. 203). I would add that how peer tutoring is theorized and conceptualized is equally important and the first step to a revisioning of its contribution to writing centers and peer learning across the academy.

\section{Critiques of Peer Learning}

Evidence that the field of writing center studies has work to do in describing the potential for peer tutoring are perceptions and assumptions from outside the field that draw its potential into question. An example of the under-valuing of alternative learning theories that feature peer tutoring can be found in recent debates in higher education. The persistence of the "literacy crisis" argument, whose supporters call for more rigor and individual accountability (with varying conceptualizations of both), also question whether alternatives to individualized instruction such as peer-facilitated study team learning offer any benefits beyond what they term socialization (Arum and 
Roksa 2011, p. 68). This dismissal of peer learning and the impact of various forms of socialization from important conversations about learning in the academy is problematic. It has the potential to invite dismissal of more formal and innovative efforts to support productive learning such as the peer learning taking place in writing centers.

One such challenge to the value of peer learning and call for more rigor and demanding assignments in the classroom comes from the authors of Academically Adrift: Limited Learning on College Campuses (Arum and Roksa 2011). Their initial findings (a second book based on the data is forthcoming) is fueling major debates across many college campuses. While a critical focus of the sort of longitudinal research project conducted by these authors is important and some of the discussions productive to addressing current issues in education, others have taken up the debate in potentially damaging ways. Drawing solely on responses to the College Learning Assessment (CLA) ${ }^{1}$, media and educators have focused on the most startling conclusions of the study: students demonstrate no significant improvement in a range of skills.

\footnotetext{
${ }^{1}$ The College Learning Assessment (CLA) is a standardized test developed by the Council for Aid to Education and the RAND Corporation. It is an online assessment tool designed to measure student progress in critical thinking, analytic reasoning, problem-solving, and writing. According to the Council, "to date, over 500 institutions and 250,000 students have participated in the CLA (CLA, 2012)." Assessment data from the council's first survey of 24 institutions from 2005-2007 is the primary data set for the findings of researchers Richard Arum and Josipa Roksa (2011), authors of Academically Adrift: Limited Learning on College Campuses.
} 
Arum and Roksa (2011) argue that their results indicate that students should spend more time studying alone and less time studying with peers; instructors should assign more reading, more writing, and have more contact and higher expectations for students. While these conclusions in and of themselves are not problematic, some have interpreted the results as making a case against the value of peer learning and pedagogies such as collaborative learning in general. Arum and Roksa (2011), for example, view active/collaborative learning as primarily a tool for engagement at the expense of demanding coursework and frequent individual assessment. In terms of peer interactions, the authors identified one "notable difference: students who entered college with the highest academic aptitude spent proportionally less time studying with peers than students who came in with less prior demonstrated ability" (p. 68). The authors also note that recent institutional practices "encourage students to attend peer study groups designed to support learning and enhance collegiate social integration and retention" (p. 69). They question whether encouraging social integration is necessary and further argue that there is not enough evidence and research to support the value of peer study groups.

Arum and Roksa's (2011) study and the resulting attention and praise it has received is a good example of the continued dominance of an individualistic model of learning and an autonomous model of literacy (Street 1984). Barton and Hamilton (1998) argue that any theory of literacy implies a theory of learning (p. 12). This statement is equally sound in reverse: any theory of learning implies a theory of 
literacy. Dominant assumptions about literacy work to entrench theories of learning that focus on individualized instruction at the expense of a greater understanding of the dynamic, interactive, and social nature of learning and literacy. For example, "Literacy crisis" debates are not new and are intertwined with what Harvey Graff (2011) has termed the literacy myth. Graff has chronicled the staying power of these debates since the 1970s and argues, "The power of the literacy myth lies in the first place in its resiliency, durability, and persistence. It serves to organize, simultaneously focus but obscure, and offer an explanation for an impressive array of social, economic, and political assumptions, expectations, observations, and theories, on the one hand, and institutions, policies, and their workings, on the other hand" (p. 63). Graff (2011) argues that literacy by itself has been conceptualized as “independently transformative" (p. 4). Instead, "literacy's influences are mediated by a host of other intervening factors of a personal, structural, or cultural historical nature rather than universal" (p. 4). Graff's argument is consistent with James Gee (1996), Brian Street $(1984,1995)$ and others in New Literacy Studies who demonstrate the limitations and consequences for learning when literacy is viewed narrowly as the ability to read and write (sometimes referred to as "functional" or "traditional" literacy). Gee (1996) argues that "literacy as 'the ability to read and write' situates literacy in the individual person, rather than in society" (p. 22). One of the clear limitations of such a restrictive notion of literacy is that it perpetuates an equally traditional and long-since discredited concept of reading and writing as essentially 
solitary, non-transactional actions. Street $(1984,1995)$ terms this dominant view of literacy as the autonomous model, which promotes literacy as a technical skill that leads to advances in certain cognitive abilities, is crucial to a productive society, and can be learned in a context-free environment.

The type of renewed focus on peer learning emerging from the debates outlined above may also contribute to the questioning of the value of writing centers at a time when economic and political pressures are making some programs targets of cutbacks. Debates such as those fueled by the conclusions in studies such as Academically Adrift also cast doubt on long standing work based upon social theories of learning such as Etienne Wenger (1998) and others. For example, George Kuh, Katie Douglas, Jon Lund, and Jackie Ramin-Gyurmek (1994) argued, “students learn course content through their interactions with others (p. 53)." Writing center programs such as the Michigan Tech Writing Center study teams provide an opportunity to determine whether this type of peer interaction has the potential to create the "learning rich context" that Kuh et al. insist "learning demands" (p. 53) as well as what added value beyond learning course content might emerge from this type of setting.

Within the field of writing center studies, these debates also offer an opportunity for writing centers to challenge their own assumptions and understandings of peer learning and "best" practices. I argue that the Michigan Tech Writing Center's study teams are representative of the potential for peer learning when it emerges from participatory designs among students (team leaders and participants), teachers, and 
administrators (writing center directors) and is informed by social theories of learning (Wenger 1998, Lave and Wenger 1991, Kuh et al. 1994) and broader understandings of literacy (New London Group, 2000). For example Wenger (1998) argues that a learning community may be formed when a community of practice develops a social infrastructure that gives new members access to experienced members, pays attention to how new identities are proposed and existing identities reconciled, and allows for meaningful participation by members in the design and work of the community. While the study teams were designed to support students enrolled in a specific course where their individual performance and content knowledge would be tested and assessed, the study teams also offer a site where students share experiences, question and discuss content, and thus potentially create new knowledge, open new identities, and develop new practices.

\section{From Peer Tutoring to Peer Learning}

The learning model I see emerging from the study team suggests to me that a new vision of peer tutoring is needed in writing centers and across the university. For example, Writing Centers have a long history of individualized instruction and peer tutors have been traditionally positioned as the knowledgeable other, helping writers (often characterized as "underprepared") to become "better writers" (North 1984, "Idea of a Writing Center"). Emphasizing how writing centers differ from the classroom, the writing center identities emerging from early scholarship positioned writing centers as an alternative form of instruction within the academy, but as one 
that still focused on the individual writer. Writing centers were described as "committed to individualized instruction, to taking the student out of the group and to looking at her as an individual, as a person in all her uniqueness" (Harris, 1990, p. 19). Whether teacher or peer tutor, this history and understanding of peer tutoring aligns with what Hawk (2007) has described as "dialectical pedagogy" where the knowledgeable expert leads the student to the desired point.

John Trimbur (1989), Nancy Grimm (1999) and more recently Geller et al. (2007) have called for researchers to move beyond the tutor/tutee dyad when exploring writing center work. This suggests a shift to an emphasis on peer learning, including its importance to the work of academic institutions in areas such as supporting diversity, addressing race and racism, and engaging students in meaningful learning experiences.

\section{Focus of the Study}

Etienne Wenger (1998) argues that academic institutions, "to the extent that they address issues of learning explicitly, are largely based on the assumption that learning is an individual process, that it has a beginning and an end, that it is best separated from the rest of our activities, and that it is the result of teaching" (p. 3). In contrast, Wenger believes that learning is ubiquitous, distributed across a variety of contexts, and like the literacy practices that embody it, is patterned by social interactions and processes. In this dissertation, I align with Wenger and argue that within academic institutions, writing centers are uniquely situated, socially rich sites 
for exploring learning and literacy. In particular, I examine the work of the Michigan Tech Writing Center's ${ }^{2}$ UN 1002 World Cultures study teams primarily because in these teams, students are actively engaged in structuring their own learning and meaning-making processes and thereby, are enacting an alternative view of learning and literacy.

The learning model at work in the study teams represents an alternative to traditional teacher-centered classroom models and writing center pedagogies that emphasize an individualistic approach to learning. This dissertation explores the potential that an alternative perspective on learning, one informed by social theories of learning, has for contributing to new understandings of learning and literacy in writing centers and across the university.

I chose to study the Michigan Tech Writing Center's study teams, which were developed primarily as support for a large-lecture general education course, for three major reasons:

1) Unlike traditional classroom and writing center models of learning, students (Writing Center coaches ${ }^{3}$ and the student participants) have a high degree of

\footnotetext{
2 The Michigan Tech Writing Center was the name of the Center at the time of my study. In 2010-2011, the Center became The Michigan Tech Multiliteracies Center (MTMC), a name more descriptive of its mission to "address the challenges of learning and communicating in complex and culturally diverse environments."

${ }^{3}$ In writing centers, what to call staff-tutors, consultants, or in the case of the Michigan Tech Writing Center, coaches - typically emerges from a meaningful connection to the learning relationship at work in sessions. Study team coaches, in part, facilitated team meetings, developed materials, and tracked team attendance.
} 
autonomy in the teams' design and evolution. This raises a number of questions for me: How do writing centers prepare and support staff for this type of work? How do study team participants negotiate the way the teams will be structured? While this suggests that students are major decision-makers in the team design, I also want to know how the structure of the course (UN 1002 World Cultures) and the Writing Center support structure and policies affect the study teams.

2) The study teams differ from most group tutoring models in that an individual writing project is not the focus of the session. Students have writing assignments for the course and an occasional team session will feature discussion of a particular writing assignment; however, the primary "work" of the teams focuses on making meaning and understanding the content of the course. This is relatively new territory for writing center work and calls for a broader understanding of literacy and the scope of writing center work. What features of writing center pedagogy make writing centers uniquely situated to take up this kind of work? How might a better understanding of team learning contribute to the field of writing center studies?

3) The study teams also represent a unique opportunity to study authentic literacy and learning practices within a team-learning context. For example, study team participants bring a variety of practices, skills, and experiences to the team, which may change, adapt, or even be discarded as teams address the joint enterprise of learning course content. This suggests that study team sessions are not only potentially rich sites for exploring the conditions that support learning and define writing center 
work, but also provide an opportunity to examine how learning and literacy development is linked to identity and participants' learning trajectories. How does the experience of leading and participating in a study team contribute to the writing center coaches' and students' overall literacy and learning development?

\section{Research Question and Benefits of the Study}

Bringing these three areas of interest together, the over-arching question that this dissertation investigates is what are the factors and conditions that define and support learning and literacy development in a study team setting? Other important questions will be how do writing center coaches shape learning in this context and how does the experience of working in this type of setting shape the coaches' learning trajectories? How does the view of learning and literacy emerging from this type of setting challenge and provide an alternative to more dominant learning models such as individualized instruction? And finally, what is the significance and potential of a better understanding of this view of learning and literacy to the field of writing center studies and higher education in general and particularly to the ways learning environments are conceptualized and developed?

Investigating the questions above will benefit scholars and educators in important ways. I believe it will offer a much-needed alternative model of learningone that challenges the continued dominance and focus on individualized instruction. The study also will provide an opportunity to apply concepts and interrogate claims from literacy studies in "natural" settings, such as those conducted by Barton and 
Hamilton (1998), Brandt (2001), Heath (1983), Street (1984 and 1995), Lave and Wenger (1991), (Wenger 1998) and Gee (2003). Such an opportunity may also provide a more concrete example of the application of The New London Group's (2000) call for a "pedagogy that provides access without people having to erase or leave behind different subjectivities" (p. 18).

Additionally, a study that focuses on team learning in a writing center context can provide support for the importance of developing more meaningful learning experiences for students across the university and for rethinking students' contribution to the work of the university. When writing centers assume more complex roles within the university, the coaches also are being asked to negotiate new roles and levels of intellectual activity. The Michigan Tech Writing Center's study teams are a good example of just such demands on writing center coaches. For the teams that I observed, coaches developed materials and activities in coordination with other students and demonstrated an intellectually sophisticated understanding of learning and an ability to use the structure and pedagogical support provided by their Writing Center directors and coach education course in ways that contributed significantly to not only decision-making in the teams, but also in the design and structure of the Writing Center.

This study will also contribute to the field of writing center studies by adding to discussions that seek to move beyond a focus on the idealized (and romanticized) one-to-one tutoring session. I see this project not as something that will dismiss this 
pedagogical staple of writing center work, but one that will in part question its continued dominance in light of emerging understandings of learning and meaningmaking.

To address these gaps in understanding, my dissertation investigates an alternative model of learning, one informed by social theories of learning and literacy and enacted through the activities and experiences of the Michigan Tech Writing Center's coaches as they lead UN 1002 World Cultures study teams. My research reveals that the learning taking place in the teams is closely linked to identity formation and that leading the teams is an important component of the coaches' overall educational experiences. My research also reveals that supporting this type of learning in writing centers and across the university requires an expanded definition of literacy and significant changes to how learning environments are conceptualized and developed.

In Chapter 2, I link scholarship from social theories of learning (Wenger 1998, Lave and Wenger 1991), literacy theory (New London Group 2000, Grimm 1999, 2011, Street 1984, 1995, 2001, Barton and Hamilton 1998) and composition studies (Syverson 1999, Cooper 1986). I describe my data collection process and the analytical framework that I use to develop an understanding of the type of learning enacted in the Michigan Tech study teams. In Chapter 3, I draw on data collected from interviews and observations of the study teams as well as my own experiences as a study team coach and UN 1002 teaching assistant to illustrate how the enaction of the 
program design for the teams includes emergent interpretations and practices. I argue that this type of student-directed learning is an important contribution to the work of writing centers and the university. In Chapter 4, I narrow the focus to the experiences of one coach to explore the connection of identity to supporting successful learning ecologies. I argue that writing center work emerging from a design that incorporates identity formation as a key element of learning provides valuable learning experiences for the coaches and a vital learning environment for students using writing center services. In Chapter 5, I address the implications of my research for writing center studies and higher education in general. I argue that designing learning contexts that cultivate and support the formation of new identities is complex, involves a flexible and opportunistic design structure, and requires the availability of multiple forms of participation and connections across contexts.

\section{Writing Centers as Research Site}

At the time of my study, I was in the position as a researcher who was both a study team coach and teaching assistant for a section of the course, UN 1002 World Cultures. From this perspective, I began to view a project focused on the study teams as an opportunity to study authentic literacy and meaning-making practices within a team learning context. Because of the large volume and variety of material required for the course, study team sessions also offer a site for exploring the conditions that support team learning and what New Literacy scholars refer to as literacy events and literacy practices (Heath 1983, Heath and Street 2008, Barton and Hamilton 1998), 
and they also are sites for exploring the ways these practices shape and define writing center work. Understanding more about the scope and potential for this type of writing center work could contribute to broader understandings of how learning emerges and is distributed across the curriculum in ways that studies focused on classrooms, course design, and teaching cannot.

This type of research also aligns well with recent scholarship in the field of writing center studies that have given increased attention to the ways the work of writing centers contributes to the broader curricular goals of the institutions within which they are situated (Geller et al., 2007; Lundsford and Ede 2011). While writing centers have a long history of providing one-to-one tutoring support to composition programs (Harris 1986, Boquet 1999) and more recently writing across the curriculum initiatives (Hall and Hughes 2011), new contributions to the field have argued that writing centers have the potential to cultivate a "culture of learning" within their centers and across the university and be "ground-level indicators" of how learning takes place (Geller et al., 2007; Lundsford and Ede 2011). The study teams are "ground-level indicators" of the conditions that support an alternative to an individualistic model of learning, a type of student learning that is often over-looked and under-investigated.

The idea that what happens in writing centers has much to teach us about learning and the conditions and practices that support learning may not be surprising to those who work in writing centers, yet there has been little research in this area. 
One possibility for this gap in research might be due in part to how deeply invested writing centers are in the one-to-one tutoring model. For example, the International Writing Centers Association (IWCA), a National Council of Teachers of English (NCTE) Assembly, provides resources on its website for administrators and others interested in learning more about creating and supporting a writing center. In a SLATE Statement (Support for the Learning and Teaching of English) prepared by Muriel Harris in 1988 and titled "Concept of a Writing Center," the following defining characteristics of the writing center concept are listed: "Tutorials are offered in a oneto-one setting; tutors are coaches and collaborators, not teachers; each student's individual needs are the focus of the tutorial; experimentation and practice are encouraged." An important point regarding the last characteristic is that encouraging experimentation and practice refers to the student, not the tutor or coach.

Another explanation for a lack of research on learning in writing centers is that writing center scholarship has long-centered on a "struggle against perceived marginal status" within the academy (Kinkead 1996, Harris 2002). In the same IWCA resource noted above the "status" of the writing center is listed as an issue and concern. Some have argued for a more theorized understanding of practice and challenge the productiveness of linking writing center identities to one of marginalization (Grimm 1999), while others have adopted metaphors that isolate the writing center from the rest of the academy, for example, as a "safe haven." I do not want to suggest that writing center administrators should stick their heads in the sand regarding potential 
threats to enacting the center's mission, or that it is a negative idea for students to believe the writing center is a place where they can work on projects in an environment different than the classroom; however, writing centers limit their influence and potential within the university and therefore their ability to advocate for student learning when they attempt to isolate themselves theoretically or materially. Instead, the very position of writing centers in the university makes them uniquely situated 1) to provide meaningful learning experiences for both students and coaches, 2) to advocate for student learning, and 3) to conduct valuable research on learning and literacy. I view the research I conducted not as from the perspective of marginalized other but from a site in the learning ecology of the universityinextricable intertwined in both positive and negative ways.

For my project, I view the Writing Center as an open rather than closed, isolated site within the university. This perspective requires an approach to research that allows for a focus on the work of the study teams but at the same time doesn't exclude the larger infrastructure of the Writing Center and the classroom. It also requires paying attention to other "boundary areas" that overlap with the work of the study teams and learning experiences of the coaches and study team participants. In other words, the unit of analysis needs to encompass more than an aspect of the teams. It also needs to include recognition of the teams as situated in a dynamic rather than static learning ecology. 
Margaret Syverson (1999) has defined an ecology as an intricate web of interactions and processes involving both living and nonliving entities (p. 73), a set of interrelated and interdependent complex systems" (p. 3). Applying this concept to the study teams helps me recognize the ways resources for learning, including policies, textbooks, and other "non-living" entities, structure learning. It also helps me to understand how the experience of coaching a study team influences the coaches' overall learning trajectories. Because I believe that learning is ubiquitous, and that it cannot be separated from the activities, social processes, and literacy practices that embody it, thinking in terms of a learning ecology provides a useful framework for viewing the Writing Center as an open system and allows me to explore how other elements and structures - the UN 1002 classroom and coach staff education activities, for example, shape and are shaped by the activities and work of the teams.

Ecological models have become increasingly popular in a number of fields, primarily because they are useful to understanding complex systems of processes and relationships. They offer ways to account for the dynamic interactions taking place in an environment that narrowly focused and static models cannot. While not as evident as its use in the sciences, a growing number of compositionists, literacy, and writing center scholars have been drawing on ecological models to shift the focus from individual writers to broader systems of writing and definitions of literacy. Margaret Syverson (1999), for example, has developed a theory of composing as an ecological system, extending Marilyn Cooper's (1986) “ecological model of writing.” Both 
Cooper and Syverson's work challenge “common cultural assumptions about mind, language, and society" (Syverson p. 25), in particular, that cognition is located in (and the property of) individuals, while at the same time they address questions about human agency that a broader understanding of mind, activity, and experience proposes. Byron Hawk (2007) also argues for more ecological pedagogies with an emphasis on "systems, dynamic change, and complexity" as well as "an emphasis on situatedness, and an acceptance of the unconscious or tacit elements of lived experience" (p. 224). In literacy studies, David Barton (1994) uses what he describes as an ecological metaphor to frame discussions of changing views of literacy. Also drawing on ecology as a generative metaphor for research, Fleckenstein et al. (2008) propose an "ecological approach because that metaphor highlights the degree to which all research approaches are interpellated with the practices of other approaches, an orientation that directly implicates local diversity" (p. 402).

For me, the study teams are part of a learning ecology and so ecology becomes not only a framework for understanding how learning and literacy are enacted in a study team, but also it helps to identify processes, patterns, and practices that hinder or support learning and literacy development. An ecological model also aligns well with social theories of learning and literacy. Linking these three theoretical strands together is the topic of Chapter 2. 



\section{Chapter 2}

\section{Enacting a Social Theory of Learning}

In this chapter, I want to 1) foreground the theoretical framework for my analysis, and 2) describe the study teams and my approach to data collection. One way of developing a better understanding of team learning and the conditions and structures that support it is by linking concepts from New Literacy Studies (NLS) and social theories of learning. The result, I argue, is a more ecological approach to research, and one that recognizes that learning and the work of writing center professionals, teachers, and students is enacted within dynamic interconnected systems. This approach, which I outline below and use to explore, understand and analyze study team learning, helps me to focus on learning in ways that more traditional forms of assessment and analysis cannot. For example, I have noticed that in my work one-to-one with students, as a study team observer and coach, and graduate teaching assistant for a section of UN 1002 World Cultures, individualcentered forms of assessing and understanding the "success" or "work" of the teams (grade for the course or specific assignments, retention, evaluations, group process forms) lack the explanatory power to address factors much beyond individual performance. While these forms of assessment are useful in terms of understanding an endpoint and providing contrast to an ideal or standard, they do little to help me understand how these teams work and how team participation shapes the learning experiences of the Writing Center coaches. 


\section{Studies of Team Learning}

While there has been some research conducted on the ways working in a writing center shapes the learning experiences of coaches (Hughes, Gillespie, and Kail 2010), I am not aware of any long-term qualitative, research on content-level team learning within a writing center context. Hughes et al. (2010) focused primarily on the experience of one-to-one tutoring. Their work provides important evidence of the value of this type of learning experience as it applies beyond college; however, their use of Bruffee (1978) as the primary theoretical framework for defining peer tutoring and liberal education provides a narrower focus than what my unit of analysis dictates. For example, their emphasis on the value of collaborative learning as defined by Bruffee doesn't help me to understand the tensions and conflicts faced by the coaches as they come in contact with and negotiate multiple perspectives on learning and literacy.

In a similar way, the theoretical frameworks used to analyze group tutorials in writing center settings exclude the distributed nature of learning that team learning makes visible. In their comprehensive review of writing center research, Babcock and Thonus (2012) identify three studies that focused on group tutorials. Two of the studies, Hess (2008) and Montgomery (1994), worked from a theoretical framework aligned with expressivist models of teaching writing and Bruffee's (1999) model of collaborative learning. In describing these studies, Babcock and Thonus (2012) noted that tutors in the semester-long writing center groups that Hess examined were 
"trained in and trained writers in the type of response recommended by Elbow and Belanoff," (p. 78) whose work is associated with expressivist pedagogies. In part, expressivist models of teaching writing focus on the voice of the individual writer and work from the assumption that meaning is embedded within the writer, who needs to find the language to express it. The groups' role in expressivist pedagogy is to respond as readers to the individual writer's text while the writer remains silent, taking notes that will guide revision. Some argue that expressivist pedagogies can contribute to more active and engaged learning contexts. As Christopher Burnham (2001) notes, scholars such as bell hooks and Randall Freisinger have argued that expressivist strategies can align with liberatory or engaged pedagogies that repair "the habitual dichotomizing of conventional thinking, repairing splits between body and mind, intellect and spirit, teaching and learning, and theory and practice" (p. 33) and attend to the ideological nature of writing and social embeddedness of meaning. In this sense, expressivist pedagogies seemingly have the potential to move beyond a narrow focus on the individual; however, Hess draws on Vygotsky and Bruffee as a way to analyze learning in this context (Babcock and Thonus 2012). This constructs a theoretical framework based on views learning as a process of "internalization" of knowledge rather than learning as increasing participation.

According to Babcock and Thonus (2012), Montgomery's study focused on the ways writing center peer tutors facilitated talk in group workshops. Quoted in Babcock and Thonus, Montgomery's study emerged from her belief that "helping students 
acquire useful meta-language for talking about their emerging texts may be the tutors' most important role in facilitating an effective writing workshop" (p. 77). This approach also resonates with Bruffee's (1984, "Peer Tutoring”) notion of "conversation," which I described in chapter one and that seeks to inculcate writers into a particular "normal discourse." More promising for my purposes was the third study described by Babcock and Thonus, a sociolinguistic analysis of L2 writers participating in writing center peer groups: Gilewicz and Thonus (2001) and Thonus (2003). The researchers studied transcripts of group sessions looking for "strategies in the negotiation of meaning, patterns of student solicitation for feedback, and the pragmatics of language in utterances related to the evaluation of student writing and to suggestions for revision" (p. 78). Social linguistics has influenced some areas of New Literacy Studies (Gee 1990) and this study revealed some interesting results regarding group interactions; however, because L2 writers' feedback appeared to be rejected by other group members, the researchers called for more research and concluded that based on their research, writing center facilitated peer writing groups may not be effective for L2 writing development (p. 78). This suggests to me that applying a sociolinguistic framework to my study would leave many unanswered questions and perhaps a premature dismissal of this form of writing center work.

Despite all three studies focusing on group tutorials in writing centers, the emphasis remains on individualized models of learning, which does little to help me understand the dynamics of team learning. More importantly for my study, these 
approaches and others that operate from a tacit understanding of learning and literacy don't help me to uncover important factors and conditions affecting the study team ecology. They don't make explicit the underlying assumptions that structure learning and representations of literacy, nor do they help me to understand study team learning as an experience of participation.

\section{Ethnographic Approach}

Because I am most interested in unquantifiable aspects of literacy and learning, such as the importance of the relationship of newcomers and old-timers and the connection of identity to learning trajectories, an approach to research based upon ethnographic methods seems well-suited. In describing his ethnographic approach to studying national literacy programs Brian Street (2001) argued that the task of research is "making visible the complexity of local, everyday, community literacy [and I would add learning] practices and challenging dominant stereotypes and myopia" (p. 7). The theoretical assumptions and concepts that frame Street's approach are relevant to my study in three important ways. First, he challenges representations of literacy that he finds in traditional literacy programs that define literacy narrowly as a measurable technical skill—what he terms as the "autonomous model of literacy." Second, he argues that instead, literacy is always ideological, "rooted in a particular world-view and a desire for that view of literacy to dominate and to marginalize others" (p. 8). A third important aspect of Street's concepts that influence my study is that his representation firmly situates literacy as a social practice rather than a neutral 
skill. Street's identification of the autonomous and ideological models of literacy provides a framework for understanding how the representation of literacy in different contexts affects learning and literacy development across contexts. By that I mean that while the Writing Center may view literacy in one way, and design its programs based upon an understanding of literacy as ideological, the dominance of the autonomous view of literacy may circulate by way of structuring resources from the course and the prior experiences of students and coaches. For my study, it is important that the theoretical framework "makes visible" this clash of ideologies and the ways coaches recognize and navigate these tensions.

Recognition of these tensions also acknowledges the complexity of this type of writing center work. While literacy and learning are context dependent, they also are situated within a larger context or ecology. This not only suggests that the writing center study teams are affected by structures, histories, and systems beyond the Writing Center, but also, as the Writing Center coaches have observed, that their work creates a "ripple effect" within the Writing Center, the larger ecology of the university and even more broadly when they attend and present at professional conferences.

Street's (2001) concepts also posit that literacy is "is rooted in conceptions of knowledge, identity, being” (p. 7). In this sense, literacy and learning are what Maturana and Varela (1987) have termed "structurally coupled," and I argue that Street's concepts can also be applied to models of learning. Street (2001) and others in the field of New Literacy Studies have much in common with those who argue for a 
social theory of learning, such as Etienne Wenger (1998). Before I move into concepts from Wenger, there are some additional important aspects of literacy theory that contribute to my framework.

\section{Literacy Events and Enaction}

Linking the concepts of literacy events and enaction to the study teams allows me to explore not only potential restraints within and upon the system, but also the ecological conditions that support learning within the system. By focusing on literacy events, researchers such as Heath (1983), Street (1995) and others in New Literacy Studies shift the emphasis from individual development to the collection of practices, activities, and experiences associated with literacy. In terms of analyzing the work of the study teams, the concept of literacy events offers a useful unit of analysis for a research project designed to analyze the ways coaches enact a particular view of learning and literacy. For example, the learning games that the coaches designed for the study teams can be viewed as a literacy event.

The concept of literacy events emphasizes the notion that literacy takes place in a social context—it is situated. Heath (1983) conceptualizes a literacy event as "any occasion in which a piece of writing is integral to the nature of the participants' interactions and their interpretative processes" (p. 93). The literacy event in Street's (1995) terms is "underpinned by systems of ideas and organization that are not necessarily made explicit in the immediate discourse" (p. 133). In other words, these are "any kind of conventions which people internalize" (p. 133). Street (1995) argues 
further that we have "culturally constructed" models of the literacy event in our minds. The concepts are helpful to understanding why certain "texts" and ways of makingmeaning seem to hold more value to study team participants than others, as well as how coaches may draw on previous experiences to shape learning in the study team context.

Finding an approach to considering an entire system while focusing on literacy and learning is a challenging project. In addition to literacy events, the concept of enaction as developed by Syverson (1999), offers a way of narrowing the focus to the activities and interactions within the teams and Writing Center as a whole while at the same time attending to the complex ways these interactions and activities bring forth a particular view of learning and literacy. In this way, tensions among representations of learning and literacy may be uncovered, which could lead to a better understanding of how practices that mediate and negotiate these tensions emerge.

Enaction, as defined by Syverson (1999), assumes that "knowledge is the result of an ongoing interpretation that emerges through activities and experiences situated in specific environments" (Syverson p. 13). Meaning-making emerges through the ways the activities and resources developed by the coaches are taken up by study team participants - their practices. The idea that meaning is enacted is emphasized by the phrase "all knowing is doing" from Maturana and Varela (qtd. in Syverson p. 14). Applying the concept to writers composing texts Syverson notes, "We can see enaction at work as writers interpret their experiences and ideas in texts that emerge 
from continuing activities and experiences with their environments ..." (p. 17). Gaining a better understanding of how various agents in the study team ecology use their interpretations of this environment to engage in purposeful activities and interactions is an important step toward understanding this type of writing center work.

Describing ecological systems, Syverson writes, "Throughout these systems, agents are engaging in activities to coordinate themselves with each other and with their environment. These activities are interrelated and interdependent; in the process, the agents are constructing a world, as well as responding to it" (p. 68). Coordination in this sense includes adaptation, but not exclusively so. It is also reciprocal. She adds, "Yet they exist and operate not as isolated individuals but in a network of relationships structured by the activities of other agents in particular situations" (p. 68). For Syverson (1999), this raises questions about the types of activities and practices that make up the composing of a text. For the study teams, this draws attention to how the coaches and team participants interact with each other and how these interactions contribute to the evolution of the program and Writing Center practices - through their interactions and activities, they are "constructing a world."

This understanding of enaction also points to the importance of studying the teams over time. I have noticed that activities designed to tackle the at times overwhelming amount of content for the course evolved over the semester. In one team, for example, team members initially decided to divide equally the readings and study 
questions among them. The beginning of each team session was spent passing out copies of the individual responses. During some meetings, individual students would then read through the responses he/she created. Due to time limitations, this was often done quickly and discussion of the responses did not often take place. In some groups this practice worked "efficiently" with each individual member receiving a complete set of study questions. In other groups the distribution of responses to the study questions broke down when some members didn't complete their assigned sets of questions, or some members' responses were less developed than others. The initial response to this problem was to "force" the system to work. Coaches and team members tried a number of ways to encourage full participation. Another response was that some students began completing all the questions on their own, not wanting to rely on other students for study guides. Yet another response was to begin developing responses to the questions during the team sessions.

What strikes me in this example is that while unexpected behavior caused initial tension, it also led to the emergence of a more interactive learning strategy for structuring the activity. By talking about the study questions within the team, the resources that each member brought to the team were available designs for making meaning. In the team where everyone did his/her part, the initial goal of the activity was to provide a benefit to the group but the possible resources for making meaning were limited. In the team where the activity worked "efficiently" the plan for the 
distribution of learning began as a cooperative strategy yet evolved into a more individualized learning situation.

In the next section, I want to describe several key concepts, primarily derived from the work of Etienne Wenger (1998), which I use for my analysis of study team learning. His richly textured articulation of a social theory of learning shifts the emphasis from individualized instruction and locates learning as a process of participation.

\section{Learning Defined as Increasing Levels of Participation}

Lave and Wenger (1991) and Wenger's (1998) concepts of participation and non-participation add another layer to the ways literacy events and enaction contribute to a richer understanding of learning. Jean Lave and Etienne Wenger (1991) suggest that situated learning is enacted through "legitimate peripheral participation." Their study of apprenticeship examines participation in terms of changing relations and the relations among "newcomers" and "old-timers." As a form of enaction, their concept provides a means of analyzing student study team participation and non-participation as well as the Writing Center coaches' growing involvement in the work of the Writing Center and the University.

Lave and Wenger (1991) use the concept of legitimate peripheral participation to "characterize the process by which newcomers become included in a community of practice" (p. 100). Unlike Bruffee's (1984, "Peer Tutoring”) concept of "conversation" and other influential theories of learning (Vygotsky and Piaget for example), 
legitimate peripheral participation is not an internalization of autonomous and measurable sets of skills. Instead, the concept captures certain conditions under which people can become members of and identify with a community of practice. Lave and Wenger argue that another difference in a learning model based on participation is that the "required learning takes place not so much through the reification of a curriculum as through modified forms of participation that are structured to open the practice to nonmembers" (In Wenger 1998, p. 100). Peripherality and legitimacy are "modifications" that allow for varying forms of participation. They add that it is this participation in a community of practice that becomes the curriculum. Understanding how newcomers become participating members of a community of practice is of particular importance to my study. On one level, I am interested in why many study team participants choose to become Writing Center coaches, and on another level, I am interested in how the interactions of newcomers and old-timers contribute to the practices and structure of the Writing Center.

Another important distinction between Lave and Wenger's concept of learning as participation and traditional models of learning is that it makes visible the limitations of so-called collaborative models of learning. Bruffee's (1984) view of learning is often associated with collaborative learning ("Collaborative Learning"). As noted in chapter one, collaborative learning and its connection to peer learning has been problematic in a number of ways. Wenger (1998) argues that participation "is not tantamount to collaboration. It can involve all kinds of relations, conflictual as well as 
harmonious, intimate as well as political, competitive as well as cooperative" (p. 56). This understanding of participation is helpful to identifying and exploring the tensions and clash of ideologies that circulate within the study teams and the differing perceptions of learning located in overlapping contexts throughout the University. This negotiating and mediating of differing ideologies is an important extension of the potential for peer learning. Participation in this sense suggests that peer learners (including coaches) are shaped by their experience and also shape the communities in which they participate (Wenger 1998, p. 56).

A third important element of Wenger's definition of participation is that it is a "constituent of meaning and ...broader than mere engagement in practice" (p. 57). Like Wenger's claims processors, Writing Center coaches do not stop being coaches at the end of their shifts. Wenger posits that participation cannot be turned off and on"it places the negotiation of meaning in the context of our forms of membership in various communities" (p. 57). Because coaches are members of a number of communities at school and beyond, this understanding of participation helps me think about how their experiences as coaches manifest in other contexts. For example, in chapter four I discuss how one coach makes connections between her work in the Writing Center and her chosen field of study and also shares conflicts she has encountered with others because of perspectives that don't align with values she developed from her Writing Center work. 
Legitimate and peripheral also point to the conditions necessary to support this type of participation. Peripherality suggests that a learning theory must allow newcomers to grow into full participation, and include engagement in actual practice, in learning how things work and opportunities for contributing to the overall "enterprise" of the community (Wenger 1998, p. 100). For the coaches, interactions with each other are key to new coaches' development as team leaders and to the contribution of new practices and forms of participation to the work of the coaches and the Writing Center. In the study teams, one of the primary tasks that members must negotiate is how a large amount of material will be utilized and reviewed. The idea of peripherality suggests that there should be a number of ways to participate in this enterprise. This notion challenges traditional models of learning where one desired outcome and process for achieving that outcome is perceived. Instead, coaches may need to challenge the idea that everyone must participate at the same level and look for other ways that members may contribute. As Wenger notes, communities of practice are not free of conflict.

Traditional ways of viewing a lack of participation often locate the "lack" in the individual. Instead, Lave and Wenger suggest that members, especially newcomers, may fall short of expectations or offer resistance but they must have enough "legitimacy to be treated as potential members" (qtd. In Wenger 1998, p. 101). Wenger explains that legitimacy can take many forms such as being useful or being sponsored (p. 101). In the study teams, it can mean having experiences with a 
particular culture, preparing study guides, being helpful. For the coaches, it might be encouraging a team member to become a coach, mentoring other coaches, working with coaches to create resources. Wenger argues that "with enough legitimacy all [newcomers'] inevitable stumblings and violations become opportunities for learning rather than cause for dismissal, neglect, or exclusion" (p. 101). Turning back to the study of L2 writers I discussed earlier in this chapter, considering how much legitimacy was granted those writers, given that their feedback was generally rejected, may have been useful rather than dismissing the idea of group tutorials.

Another example of the importance of the newcomer and old-timer dynamic to meaningful learning experiences is that many study team participants become Writing Center coaches. Through their participation in the teams, they see what Wenger (1998) would call the possibility of new learning trajectories. He argues that exposure to oldtimers, those "living testimonials to what is possible, expected, desirable" is "likely to be the most influential factor shaping the learning of newcomers" (p. 156). Wenger makes a distinction between what he calls "paradigmatic trajectories" and role models. He acknowledges that specific role models may be important, but the focus is always on a community and varying forms of participation. In this sense, a coach may embody the possibility of a trajectory for newcomers, but newcomers must also have access to practice and ways of contributing new ways of participating (p. 156). For Wenger, "a community of practice is a field of possible trajectories and thus the proposal of an identity (p. 156). 


\section{Learning Defined as Identity Formation}

Traditional models of learning often seek to measure internalization of knowledge and acquisition of skills. Through participation, Wenger (1998) argues that learning also is an experience of identity. The connection of learning and identity is a key element of Wenger's social theory of learning and provides a framework for understanding the relationship of newcomers to old-timers within the Writing Center community. As study team participants move on to become Writing Center coaches it becomes clear that learning and identity formation are what Wenger calls "long-term, living relations between persons and their place and participation in communities of practice" (p. 53).

A theory of learning that makes identity formation primary is not the same thing as a focus on the individual. As Wenger argues, "the concept of identity serves as a pivot between the social and the individual, so that each can be talked about in terms of the other. It avoids simplistic individual—social dichotomy without doing away with the distinction. The resulting perspective is neither individualistic nor abstractly institutional or societal. It does justice to the lived experience of identity while recognizing its social character - it is the social, the cultural, the historical with a human face" (Wenger 1998, p. 145). His understanding of identity is useful to analyzing the experiences of study team coaches as they lead study teams because he situates identity in the "mutual constitution" of community and person (p. 146). 
In chapter four, I focus on the experiences of one Writing Center coach to show how the relationship of her experiences, her access to meaningful practice and new identities was inextricably connected to the Writing Center's evolution as a dynamic community of practice. As a way to explore the role of identity to learning, Wenger's (1998) "modes of belonging" extend engagement in meaningful practice to include the ways members are able to imagine themselves as part of the community, and their alignment with the values and purposes of the community. Wenger's modes of belonging not only provide a useful framework for analyzing the experiences of the coaches, but also offer insight into the conditions needed to support the cultivation of new identities and dynamic learning communities.

\section{Designing for Learning}

Understanding the conditions needed to support learning viewed as participation in practice and as an experience of identity is another important aspect of my study. Drawing again from the field of literacy studies, the New London Group (2000) argues that "the notion of design connects powerfully to the sort of creative intelligence the best practitioners need in order to be able continually to redesign their activities in the very act of practice" (p. 20). In chapter three, I argue that this is the sort of creative intelligence employed by study team coaches as they design and redesign the activities of the teams.

The NLG further argues that "learning and productivity are the result of the designs (the structures) of complex systems of people, environments, technology, 
beliefs, and texts" (p. 20). Wenger (1998) complicates the concept of design further by arguing that "there is an inherent uncertainty between design and its realization in practice, since practice is not the result of design but rather a response to it” (p. 233). According to Wenger, the structures of practice and identity are emergent, and it is this "emergent character that gives practice and identity their ability to negotiate meaning anew" (p. 233). This understanding of design challenges traditional and more prescriptive approaches to educational design, which Wenger notes have a higher risk of being applied in unintended ways in order to meet perceived expectations. He notes the example of students focusing on test taking rather than subject matter, a common issue faced by the coaches in the study teams (p. 233).

Instead of rigid prescriptions for practice, a design for learning, according to Wenger, must incorporate the modes of belonging to form learning communities. This understanding of design has powerful implications for how Writing Center staff education and other support structures are conceived and implemented. Thinking of educational design as an "interaction of the planned and the emergent" offers a way to conceptualize the work of the Writing Center directors, coaches, and students as they become "designers" of the learning environments in which their work is enacted (Wenger 1998, p. 267). In Wenger's terms, it shifts the emphasis from the designed to designed for (p. 229).

A fundamental principle tying the concepts above together is that they are ecological. In other words, they can apply across levels of scale and can account for 
the boundary crossings that are inherent to open systems, including a university. This characteristic of New Literacy Studies and most prominently Wenger's concepts suggest this framework is applicable to analyzing other learning contexts and issues. Because the concepts above don't presuppose a specific result, they are well-suited for application to an innovative design like the study teams. In the next section, I describe the program and my approach to data collection.

\section{An Ecology of Learning}

The Michigan Tech Writing Center's World Cultures Study teams are a good example of the ways a writing center, a type of learning community, responds to change in other parts of the academy. Change in this example was a significant redesign of the University's general education curriculum. The World Cultures course, to be taken the second semester of a student's first year, was one of four core general education courses. Its large class size, up to 265 students, and ambitious goals, covering the world in 15 weeks, were primary reasons for the Writing Center offering study teams led by peer coaches. In addition to six hours of class time, students face the challenge of processing an overwhelming amount of reading, lecture notes, interpretation of international films, and written analysis of on-campus cultural events. My study was conducted in the early years of the new curriculum. At that time, students voluntarily signed up for a study team, which included four to ten other students taking the course with the same instructor. Teams met twice per week for 45 minutes each. 
Before World Cultures study teams, the Michigan Tech Writing Center looked like many other writing centers - a large, open room with individual tables for one-toone consulting sessions. In the Michigan Tech Center, bookcases, colorful posters, and a schedule board covered the walls. Natural light from the north spills into the room from a bank of windows. Plants lean northward and fill the window ledge. Two small resource rooms accessed from the main room were available for group sessions as part of an international graduate teaching assistant program, various meetings, and for more private one-to-one sessions when needed.

Offering World Cultures study teams necessitated using the resource rooms for team meetings and finding additional small meeting rooms and in some cases early on, an available classroom to accommodate several team sessions taking place at the same time. In a given hour, as many as four different teams would be meeting. Teams sometimes elected to hold their meetings in other locations, such as the student union (MUB), or outside when weather permitted.

As the study team program evolved, more rooms for study teams were added. In the team rooms, the walls were decorated with maps, affirmations, and resources produced by the team, such as a Jeopardy board fashioned from butcher block paper and colored markers. In contrast to the open space of writing center designs for faceto-face sessions, the team rooms made visible the work of the teams. The privacy of the rooms also emphasized the autonomy given coaches and students for running the sessions. 
In contrast, the UN 1002 classes were held in large-lecture halls, seating upwards of 300 students. The auditorium-style seating moves out from the stage in increasingly larger half-circles. The lighting over the seats is usually kept fairly low so as not to dilute the lighting on the large screen for projecting lecture notes, video, and other visual aids. The activities in this setting are controlled from the front by the instructor via a panel. The structure and instructional delivery methods of the course posed many challenges for students. Coaches also felt pressure to foster a depth of learning when the course structure dictated breadth. While the template style of textbook to teach culture seemed to work well for designing memory games and other quick study guides, many coaches felt it provided a surface level and sometimes even stereotypical view of culture.

The contrast in the design of these environments is obvious and one approach might be to isolate each site and focus on the limitations and advantages to learning that each site offers. Wenger's (1998) concept of learning communities offers a way to examine the relationship of these two environments to each other and to illustrate the sophisticated understanding of learning that coaches develop as they negotiate different representations of learning across contexts.

My goal is not to criticize the large-lecture classroom—many have found innovative and creative ways to offer a dynamic learning experience in this type of setting. The study teams were initially designed in part to address the limitations of a large-lecture setting and to provide large numbers of students with small discussion 
groups, thus early on establishing a relationship based upon supporting goals. Rather than evaluate the settings for learning, social theories of learning and literacy help me explore the conditions that support an active and sustainable learning environment.

This research project emerged from an opportunity, the opportunity to observe and make connections about peer learning as participation in a community of practice. The study teams were led by writing center coaches who developed materials and activities as part of structured and emergent practices. While they were provided structure and pedagogical support through a coach education course and other ongoing professional development activities, the coaches and study team participants were actively engaged in structuring their own learning and meaning-making processes.

\section{Data Collection Methods}

Analyzing practices is much like analyzing processes and social life, and as Emerson, Fretz, and Shaw (1995) note, field research is well-suited for this type of research. In considering the study teams as part of an ecology, I collected data from many diverse parts of the system. In complex systems, each part of the system is governed by its own rules and has the potential to influence outcomes (Syverson 1999 p. 7). While this characteristic of complex systems is an important starting point for looking at the ecology of the study teams, it also is important to recognize that "it is not possible to predict its behavior simply by understanding its parts and their

relationship to each other" (Syverson 1999, p. 4). Examining study teams through the 
lens of enaction allows me to account for the dynamic, distributed, and emergent qualities of the ecology as a whole. Ethnographic practices, particularly those that emphasize the importance of observation and interviewing, provide important detail with regard to activities, practices, and experiences that audio-taping alone cannot provide. As I observed the study teams, I noted how activities came to be selected or dismissed, how certain activities seemed to evolve into practice in one team and not another, how the activities, experiences, and events associated with the teams enact a particular view of learning and literacy. Further, principles that Heath and Street (2008) describe below, have guided my observations and data collection. They note,

- Gradations of change in habits and beliefs (though seemingly minor on the surface) correlate with shifts in structures and uses of language and multimodal literacies.

- Insiders or locals use tacit meaning-making processes that they take for granted, and their explanations of these often bear little relationship to realities of usage. They may be expressing ideals of behavior rather than manifest, or actual, behavior.

- The norm in (almost) all contexts is that we coordinate the regularities of patterns of several systems of symbolic structure at the same time. (p. 8) 
In addition to field notes, I collected:

Audio-taped Study Team Sessions. Initially, I audio-taped each study team session of six teams. While I continued to audio-tape each of the teams, I evaluated data and focused primarily on three teams in terms of field observations and interviewing for the remainder of the semester. For the focus of the study, I chose teams based upon the ways they contrasted with each other. In other words, I looked for teams that tended to exhibit a high degree of creativity in activities and associated practices as well as teams that seemed to choose more traditional learning approaches and practices.

Audio-taped Coach Training Class. Michigan Tech Writing Center coaches are required to take a one credit coach training course (HU 4101) each semester that they are employed by the Writing Center. HU 4101 is taught by the Assistant Director of the Michigan Tech Writing Center. During the course of this project, I audio-taped each weekly class meeting and discussion.

Interviews. I conducted individual audio-taped interviews with selected volunteers from the following groups and positions:

- Writing Center Coaches

- Students participating in Michigan Tech Writing Center study teams

- the Writing Center Director

- the Writing Center Assistant Director

- Instructors for UN 1002 World Cultures 
Course Materials. From selected UN 1002 World Cultures sections, I collected course materials, such as handouts, syllabi, assignments, and lecture notes. I also collected a variety of resources and artifacts from the study teams, including study questions, games, and other study aids.

The grid below represents the types of questions I asked individuals from each group:

Table 2.1. Types of questions asked of students, coaches and instructors.

\begin{tabular}{|l|l|l|}
\hline Students & Coaches & Instructors \\
\hline $\begin{array}{l}\text { What learning strategies } \\
\text { work best for you? }\end{array}$ & $\begin{array}{l}\text { How would you describe } \\
\text { a productive study team } \\
\text { session? }\end{array}$ & $\begin{array}{l}\text { How do you measure } \\
\text { productive learning? }\end{array}$ \\
\hline $\begin{array}{l}\text { What things are } \\
\text { memorable and why? }\end{array}$ & $\begin{array}{l}\text { What things are } \\
\text { memorable and why? } \\
\text { (From team sessions) }\end{array}$ & $\begin{array}{l}\text { most interested in } \\
\text { getting across? }\end{array}$ \\
\hline $\begin{array}{l}\text { What experiences have } \\
\text { you had that relate to } \\
\text { topics? }\end{array}$ & $\begin{array}{l}\text { What experiences have } \\
\text { you had that relate to } \\
\text { topics? }\end{array}$ & $\begin{array}{l}\text { What experiences and } \\
\text { knowledge do you }\end{array}$ \\
\hline $\begin{array}{l}\text { How have you dealt with } \\
\text { the demands of the } \\
\text { course? (reading, } \\
\text { writing, large-lecture, } \\
\text { etc.) }\end{array}$ & $\begin{array}{l}\text { How have you helped } \\
\text { students meet the } \\
\text { demands of the course? }\end{array}$ & $\begin{array}{l}\text { What do students need } \\
\text { to do to meet the }\end{array}$ \\
\hline $\begin{array}{l}\text { What are the goals of the } \\
\text { course? }\end{array}$ & $\begin{array}{l}\text { What are the goals of the } \\
\text { course? }\end{array}$ & $\begin{array}{l}\text { What are the goals of the } \\
\text { course? }\end{array}$ \\
\hline
\end{tabular}


Table 2.1. (Continued from p. 57) Types of questions asked of students, coaches and instructors.

\begin{tabular}{|c|c|c|}
\hline Students & Coaches & Instructors \\
\hline $\begin{array}{l}\text { What aspects of the } \\
\text { course contribute to } \\
\text { other areas of your } \\
\text { studies or life in } \\
\text { general? }\end{array}$ & $\begin{array}{l}\text { How do you think } \\
\text { students are using what } \\
\text { they learn? }\end{array}$ & $\begin{array}{l}\text { How do you think } \\
\text { students are using what } \\
\text { they learn? }\end{array}$ \\
\hline $\begin{array}{l}\text { How does the team } \\
\text { work? Where do you fit } \\
\text { in? How did this evolve? }\end{array}$ & $\begin{array}{l}\text { How does the team } \\
\text { work? Where do you fit } \\
\text { in? How did this evolve? }\end{array}$ & $\begin{array}{l}\text { How do you interact } \\
\text { with other professors? } \\
\text { Do you interact with the } \\
\text { study teams? }\end{array}$ \\
\hline $\begin{array}{l}\text { How will you use what } \\
\text { you learned in this } \\
\text { course? Did you learn } \\
\text { new ways of thinking } \\
\text { about things? }\end{array}$ & $\begin{array}{l}\text { Has the experience of } \\
\text { leading a study team } \\
\text { contributed to other } \\
\text { aspects of your life? }\end{array}$ & \\
\hline $\begin{array}{l}\text { Did your experiences or } \\
\text { that of team members } \\
\text { contradict information } \\
\text { from course materials? }\end{array}$ & $\begin{array}{l}\text { What information are } \\
\text { students contributing? } \\
\text { What do you do with it? }\end{array}$ & $\begin{array}{l}\text { What information are } \\
\text { students bringing in? } \\
\text { How does it contribute } \\
\text { to the course? }\end{array}$ \\
\hline $\begin{array}{l}\text { Why did you join a } \\
\text { study team? }\end{array}$ & & \\
\hline
\end{tabular}

In the next chapters, I apply my analytical framework to portions of the data collected. 


\section{Chapter 3}

\section{Negotiating Meaning: Coaches Shaping Learning}

I argued in the previous chapter that linking concepts from New Literacy Studies and Wenger's social theory of learning help me to analyze the work of the study teams. In this chapter, I apply that framework to the data I examined, which includes audio-taped interviews with Writing Center coaches, resources and activities created by the coaches and designers of the program, my own experience coaching a team, as well as observing study teams and the coach education class.

I focus on the three primary conclusions drawn from my data analysis: 1) The social model of learning emphasized by the program design along with the core values of the Writing Center are clearly evident in the data; 2) Enaction of the program design by the teams includes emergent interpretations and practices; 3) Competing models of learning as represented by the course and the prior experiences of the coaches and team participants are an ongoing point of tension and negotiation for the teams.

As a unit of analysis, I use Street (1995) and Heath's (1983) concept of the literacy event as a way to isolate certain examples from the teams while still attending to the broader ideological structures that impact them. Defined as an occasion where a piece of writing contributes to the negotiation of meaning, Street argues that the literacy event is "underpinned by systems of ideas and organization that are not necessarily made explicit in the immediate discourse" (1995, p. 133). As an example, 
viewing a team discussion of the textbook reading assignments as a literacy event can also include as part of the analysis the ways the text's reification of culture as a collection of facts to be memorized impacts that activity. Further, Street (1995) argues that participants hold "culturally constructed" models as well as "internalized conventions" of the literacy event. For my analysis, this is important to recognizing a clash of cultural models in the negotiation of meaning. For example, later in this chapter I discuss a literacy event that pitted narrative evidence against quantitative evidence. This understanding of literacy events also suggests that internalized conventions about learning and literacy may engender moments of resistance on the part of coaches and participants to the social model of learning informing the program. While literacy events provide the unit of analysis, the concepts of legitimate peripheral participation (Wenger 1998, Lave and Wenger 1991) and modes of belonging: engagement, imagination, and alignment (Wenger 1998) define a social theory of learning and provide a framework for my analysis. At the core of this theory is that learning is a form of increasing participation in a community of practice. Legitimate peripheral participation characterizes the conditions and processes by which participants, or members in Wenger's terms, become members and identify with a community of practice. Peripherality means that newcomers need opportunities to participate in actual practice, to grow into full participation, and to learn how things 
work. In this sense, both the opportunities offered to and withheld ${ }^{4}$ from newcomers must be legitimate. These concepts are important not only to understanding the conditions necessary to support participants who are newcomers to the study team model of learning, but also those conditions that support the coaches increasing participation in the work of the Center.

The modes of belonging (Wenger 1998) situate learning in practice and serve as a design as well as a framework for investigating the effects of that design. Engagement refers to active involvement in the practices of a community; imagination is a matter of seeing a role or trajectory for oneself in a community; and alignment is fitting in-believing in the work of a community. Drawing on these concepts, Nancy Grimm (2011) has argued that supporting the work of belonging means a "particular community must concern itself not only with creating access but also with transforming itself so that learners can develop meaningful identities of participation" (p. 97). Part of this willingness to transform the Center can be seen in the ways the modes of belonging and core values of the Center complement each other. In other words, the learning model implies certain core values, and the core values imply a particular theory of learning.

\footnotetext{
${ }^{4}$ In an apprenticeship model for example, a newcomer in a machine shop may not be given the opportunity to operate a particular piece of equipment on her own; however the forms of participation that she is granted place her on an "inbound trajectory" for full participation. Her peripheral participation must be legitimate in that it contributes to the enterprise of the shop. In the study teams, for example, new coaches may not be assigned multiple or large teams prior to extended interaction with more experienced coaches and legitimate participation and immersion in the day-to-day rhythm of the Center.
} 
In the initial year of the program, the Coaching World Cultures Study Teams handbook noted that the teams' design was informed by "extensive research that demonstrates that students learn best when they take an active role that includes social interaction" as well as the conclusions drawn from a 1992-93 pilot program on team learning conducted by the MTU Learning Centers (2001, p. 3).

From the first year of the program, the team design was influenced by social theories of learning that also aligned with key values of the Center. For example, the Handbook also emphasized that coaches provided a significant contribution to the planning and designing of the teams and that their "continued input will help this effort mature" (p. 3). In addition to contributing to the practice of the Center, undergraduate and graduate scholarship is also highly valued. Several coaches presented on their team experiences at regional and national conferences. Opening identities of practice to coaches in the Center was a value I saw mirrored in the teams through team building activities and an emphasis on involving team members in how material would be addressed as well as coaches encouraging team members to become Writing Center coaches.

As a core value of the Center, diversity was not a token statement for the teams or simply a result of the course topic on world cultures. Productive diversity emphasizes the idea that interactions with "multiplicity of cultures, experiences, ways of making meaning, and ways of thinking" can transform the mainstream (New London Group, 2000, p. 13). In addition to being a recurring theme in the scholarship 
of the Center's director, Nancy Grimm, an emphasis on supporting productive diversity is also evident in the Center's mission, annual reports, and employment applications. For example its mission states: "At the Michigan Tech Multiliteracies Center (MTMC, 2013), we work with students, faculty, and staff to address the challenges of learning and communicating in complex and culturally diverse environments." Included in the annual reports for the Center (and available on its website) is a breakout of staff diversity in terms of coaches who are non-majority students, as well as the variety of majors, and honors, awards, and recognition. "Openness to diversity" is listed as one of the qualifications on the Center's employment application for working in the Center. The public and internal message is that diversity matters and is welcomed at the Center. Other core values that are emphasized and evident in the teams were "relational skills, personal integrity and professional ethics, systems thinking, monitoring assumptions, and openness to transformation" (MTMC Handbook).

The relationship of the core values and the social model of learning that informs the program distinguishes it from other tutoring models set up to support learning course content such as supplemental instruction or writing fellows programs that generally require the tutor to attend classes and follow the lead of the teacher. These programs align well with Bruffee's (1984) model of peer tutoring in that they often position tutors as experts of sorts, and "little teachers" assisting the teacher. One assumption at work in these models is that without content expertise and the guiding 
hand of the instructor, peer learning will be superficial ("Peer Tutoring”). It also suggests that peer tutors operate without an explicit understanding of various perspectives on learning. For example, in a 2007 interview, Bruffee argued that "writing peer tutors both learn and teach human interdependence unawares by practicing writing as a social activity that engages tutor and tutee"(Eodice 2008, p. 37). While Bruffee acknowledges the social interactions of the tutor/tutee, he at the same time seems to be excluding the ideological structures and perspectives that influence any learning activity.

Many of the study team coaches have taken the World Cultures course or were study team participants themselves before becoming a coach; however, their leadership of the teams is not dependent upon expertise with the content of the course. Instead, the study team coaches develop a complex understanding of how learning takes place through support from the Writing Center's designs, their interactions with each other, and as they work to reconcile learning issues, such as the competing theories of learning and literacy that circulate within the teams and other communities in which they participate. For example, while a team approach to learning is common at Michigan Tech, program designs and the theoretical perspectives that inform them vary.

In this chapter, I draw on interviews with study team coaches who range in experience from newcomers to seasoned old-timers to illustrate the ways study team coaches take up the social theory of learning that informs the study team program and 
in the process enact an alternative model of peer learning. By focusing on the coaches' understandings of learning, how they apply what they know and value about learning from prior experiences, and what they are learning by working in the Center, I also want to explore how the teams work. This kind of analysis is important to understanding more about social models of learning.

I use examples, which I view as literacy events (Heath 1983, Street 1995), from the day-to-day activities of the Center and study teams as well as examples of how coaches approach trouble-shooting when learning issues arise. The concepts from Wenger and New Literacy Studies are not only important to providing a deeper understanding of a social model of learning and conditions that support it but also are important tools for designers and coaches for when things seem to "go wrong." Coaches, for example, cite what they view as a lack of participation as one of the key issues they face as team leaders. To trouble-shoot this issue, they often first look for a direct cause and effect link to why the same activities in one of their teams works better than in another, or why instituting policies for attendance and participation fail to produce the results they expect. These are methods they are familiar with through their years of experience in traditional learning environments. Wenger (1998) argues, however, that the relationship between educational designs and learning is not one of cause and effect but one of resources and negotiation - the planned (designed) and emergent (pp. 266-267). This suggests that looking to the available forms of legitimate peripheral participation would be an effective problem-solving strategy. It also 
suggests that imposing participation through additional policies may not solve the issue.

\section{The Planned and the Emergent: Putting Design into Practice}

Because the coaches have a high degree of autonomy in how the activities of

the teams are structured, the teams are important sites for investigating the "interaction of the planned and emergent" (Wenger 1998, p. 267). Designs for learning may be taken up in unpredictable ways. Many factors and conditions can affect how designs are put into practice. For example, in the study teams, competing designs for learning from the UN 1002 course or even the coaches' own experiences with learning may create tensions that, left without a means of reconciling, may shift the balance from a "primary focus on the negotiation of meaning" to the "mechanics of information transmission and acquisition" (Wenger 1998, p. 265). In other words, the coaches may feel pressure to focus on "teaching to the test" methods or learning as acquisition rather than learning as knowledge creation.

This suggests that it is important for designers of curriculum and programs to be aware of the many factors and conditions affecting their designs for learning. The Coaching World Cultures Study Teams handbook and other support resources may offer a structure and design for the teams, but as Wenger argues, design is one of the structuring resources for learning. He adds that "one can design a curriculum, but not learning" (Wenger 1998, p. 229). Learning in this sense is an "emergent ongoing 
process," and as team leaders, coaches must reconcile the team design with actual responses to that design in practice.

In analyzing my data, I looked for patterns across my interviews with coaches in the ways they talked about the design of the teams and their experiences leading the teams. I asked them what a productive study team session looked like and what things were memorable about those types of sessions. I compared their responses to the ways the design for the study teams and the core values of the Center are described in the handbook and in other resource materials provided by the designers of the study team program and Center. I also looked for ways these materials and the coaches' interactions with each other were used as resources to be negotiated in practice. In the next section, I analyze some of the coaches' responses to my questions and begin to explore the model of learning at work in the teams.

\section{Defining Productive Team Sessions: Wenger's Concept of Legitimate}

\section{Peripheral Participation in Action}

To describe productive team sessions, most of the coaches I interviewed discussed the importance of fostering conversation and discussion, team building, sharing personal experiences, utilizing the diversity of the teams, designing creative resources and activities, and participation ${ }^{5}$. Others emphasized staying focused on the task and not "going off on tangents." While "keeping students focused on the

\footnotetext{
${ }^{5}$ In Lave and Wenger's (1991 and 1998) terms, all of these strategies for learning may be viewed as forms of legitimate peripheral participation, which also may provide coaches with a way to analyze how these strategies are working.
} 
material" was a coach responsibility emphasized in the Handbook, some coaches interpreted it more narrowly and more rigidly than others. These interpretations were not necessarily congruent with the model promoted by the team designers. In my interviews, many coaches referred to the Handbook, their discussions of team strategies and goals in the coach education course, and their day-to-day interactions with other coaches and staff in the Writing Center as important influences in shaping their alignment with the list of strategies noted above. Some coaches also cited learning experiences outside the Center that impacted their approach to leading the teams. For example, some noted apprenticeship and co-op experiences or workshop approaches that they felt were valuable. Their experiences in what they described as poor learning environments were cited by some coaches as contributing to what they didn't want to see happen in the teams. This again reinforces the conclusion that the design is but one of the structuring resources for learning.

The coaches had many opportunities to think and talk about study team design and learning. Most of the study team coaches I interviewed responded with little hesitation to my question, "What does a productive study team session look like"? The vision of a productive team session they described also clearly reflected the vision defined in the Handbook. For example, $\operatorname{Rob}^{6}$ without hesitation said, "My job is to get

\footnotetext{
${ }^{6}$ The names given to coaches are pseudonyms.
} 
them to discuss the material. Whether it is through the study guides, games ${ }^{7}$, or course notes, the goal is group discussion." Group discussion and participation are the vision of learning emphasized in the Handbook. He described his favorite team moments as the times when the team would be playing games and perhaps someone wouldn't know the answer to a Jeopardy question. "Someone would say, 'Remember? That was the day we talked about [blank] in class, and we compared notes in the team.' Then, all of a sudden the student who couldn't remember would say, 'Oh, yeah now I remember.' And then that would be a springboard for a conversation."

Rob's use of the word "conversation" here may invoke Bruffee's (1984, "Peer Tutoring") model for some, but his description is a telling glimpse of how study teams led by peers working from a social theory of learning can differ from a supplemental instruction model of peer tutoring or more traditional classroom call and response methods. In Bruffee's model, a goal of conversation is to "cultivate the community life that generates and maintains the conversation from which a particular kind of thinking originates" ("Peer Tutoring" p. 209) and "the kind of conversation academics most value" (p. 211). Rather than looking for a particular kind of thinking or conversation that replicates a dominant discourse, Rob is drawing on conversation as a form of participation. He noted that in one team that he coaches the level of participation is very high and that he believes that he is learning as much from them as they are from

\footnotetext{
${ }^{7}$ Playing games to assist in the learning of course content is one of the practices that emerged from the teams. It began with one coach creating a study guide based on Jeopardy, and soon coaches were working together to create resources for the games and trying other types of game models (Pictionary, Taboo) as a form of study guide.
} 
each other. In the team where he believes the participation is low, he is concerned that there is very little learning taking place. Later in this chapter, I examine Rob's example in more detail.

In my interviews, coaches also emphasized the idea of participation being essential to productive team sessions by their use of the concept of engagement, which is one of Wenger's (1998) modes of belonging. Wenger argues that "as a context for learning, engagement is not just a matter of activity, but of community building, inventiveness, social energy, and emergent knowledgeability” (p. 237). Team building is emphasized in the study team Handbook and staff education course and is clearly evident in the development of team activities by the coaches. For example, Sue, a senior who was coaching a team for the first time, told me that the sharing of personal experiences engages students and makes them more interested in the topic. She remembered a time when someone in the class had travelled to a particular country and was sharing stories from that experience and how the team members came into the team room "already talking about it and pulling their notes out of their backpacks as if they couldn't seem to wait to share what they had just learned." She viewed the sharing of experiences as one of the best ways to learn and that was a major component of her team's practice. She noted they were most engaged when guest speakers came to the classroom or members of the team had experiences connected to the topic. These are important examples of how the practice of sharing one's experience with a topic deepens engagement and builds community. In other words, 
the practice of asking, "Has anyone travelled to the area we are now studying or know something interesting outside of the course lecture?" was a common practice that not only deepened engagement but also served as an alternative form of participation.

Other coaches who I interviewed also discussed learning in ways that not only illustrated their alignment with the program design but also with the core values of the Writing Center. For example, Rebecca described some of the "best moments" for the team she coached as coming when they had "conversations about the topic" that reflected her belief in the value of diversity, a core value of the Writing Center. In an example from one of the teams that she coached, an understanding of the value of diversity to transform the mainstream is evident. The team was diverse in terms of having students on the team from countries other than the U.S. (Nigeria, Thailand, Egypt). The conflicts in the Middle East prompted a special lecture by the instructor and Rebecca said that within the team, she was "amazed at the different perspectives on the events taking place" and wanted to use that to encourage deeper engagement. "Instead of just having them state their opinions, I would say things like what do you think someone else would think about this? In this way, it didn't get to be 'strong opinionated' arguing with each other and showed more respect for others' experiences." In this way, Rebecca was able to connect participants to the topic in new ways, a strategy emphasized in the Handbook. Her alignment with diversity and multiple perspectives as a core value became incorporated into the design for learning. 
Alignment with the core values of the Center became an important resource for Rebecca and other coaches. Many coaches believed the textbook's template-style approach to exploring the regions of the world led to an emphasis on facts as the primary representation of a region's "culture." Engaged conversation was a way to counteract the reification of culture from the textbook. In another example that illustrates transformation of the mainstream, Rebecca remembered two team members from Nigeria challenging the textbook version of marriage ceremonies in that country, which lead to a sharing of the variety of ways people can get married in other countries. She said it was particularly useful for the U.S. students in the team who also began brainstorming a list of ways Americans can "get married." For the first time, she believed, "they started to see variety and culture in their own country. They were surprised to learn that just as they thought there was one culture and one way to do things in the countries they were studying, so the other team members thought there was one way to do things in America." As a literacy event, the tension between the course model and Writing Center model can be seen in a reified view of culture offered by the textbook and how the combination of the social model of learning and alignment with core values provided a richer understanding, one that the team members saw themselves connected to.

The example above also suggests that in addition to forms of participation, learners also must be able to see their experiences as meaningfully contributing to the team. This points to the first part of Lave and Wenger's (1991) concept: legitimate 
peripheral participation. In order to reach full participation, learners must be granted legitimacy — a recognized purpose and reason for being part of the team. Wenger (1998) may be stating the obvious when he notes that if a newcomer were rejected for some reason, "that person would have a hard time learning" (p. 101).

Reflecting on an event from a team that I facilitated provides an example of why legitimacy can be an important consideration not only for negotiating tension between the classroom model and the Writing Center model of learning, but also for negotiating the clash of cultural models of meaning-making within the teams. Team members were discussing PowerPoint slides from that day's course lecture. One slide featured the term polygamy. When asked to talk about what they had learned about polygamy, several students offered the definition they had copied down in their notes. "Polygamy is the practice of having more than one wife at one time," one student said. "I think it's spouse, not wife," another said. "Yeah, a guy could have extra wives, or a woman could have more than one husband," a third added. Another student, who is from Nigeria, quietly said that the term described her family. Encouraged by the interest of the other students, the student explained that her father was considered to be an important man in their village. "His first wife could not give him any children," she said. "It is expected that a man of his importance have many children." She talked freely for several minutes about life in her village, her grandfather, and what it was like being raised by two mothers. As she shared her story, students' reactions were mixed. Although all were engaged by the story, some seemed skeptical about certain 
"facts." One student took me aside after the session and said, "There is no way her grandfather is 110 and you can go on the Internet and prove it." Sharing her experiences and negotiating meaning through narrative was important to this student and often in conflict with how other members of the team, who valued more traditional, evidence-based and verifiable methods.

The student became less and less inclined to join in discussion and eventually stopped coming to team meetings. Thinking in terms of legitimate peripheral participation helps me to think about ways I might have facilitated a more positive result. Wenger (1998) suggests that one way of granting more legitimacy is through sponsorship, which he notes is usually a requirement of apprenticeships and is part of giving access to the practice (p. 101). I could have used my position in the team to be a stronger advocate for that student as well as finding other ways for her to participate. I also could have been more aware of the impact of competing cultural models of meaning-making at work in this event. Interestingly, while the coaches I interviewed felt confident in describing productive learning and designing activities and resources to support that theory, they were much less confident in addressing and troubleshooting when things didn't seem to go well, a topic that I will discuss in more detail later in this chapter.

The work of engagement, imagination, and alignment within a community of practice can be seen in the events and description of productive team sessions. In Rebecca's session, she created a "novel situation of learning" by providing a structure 
for sharing experiences about marriage ceremony practices. Wenger (1998) argues that "in terms of participation, imagination requires an opening" (p. 186). Through her alignment with the core values of the Writing Center, Rebecca recognized an "opening," and in combination with the emphasis from the program design on engaging students in discussing the material, she provided enough structure (that was acceptable to the team members) to keep it respectful and productive. Wenger also notes that "engagement requires the ability and the legitimacy to make contributions to the pursuit of an enterprise, to the negotiation of meaning and to the development of a shared practice" (1998, p. 184). In recognizing an "opening," Rebecca took a risk in slightly altering the routine or joint enterprise of the team for a discussion that offered new identities of participation. In doing so, the U.S. students came to see their participation and contribution to the team differently and new meanings emerged.

Wenger (1998) also argues that there are trade-offs to the work of engagement, imagination, and alignment. For example, he notes that "engagement can also be narrow," adding "through engagement, competence can become so transparent, locally ingrained, and socially efficacious that it becomes insular: nothing else, no other viewpoint, can even register, let alone create a disturbance or discontinuity that would spur the history of practice onward" (p. 175). In the example from the team that I coached, the regime of competence driving what accounts for "evidence" and "facts" was tacitly enacted in ways that rejected any alternative approach to meaning-making. In the next section, I examine additional examples from the teams that suggest as 
Wenger (1998) argues, “The local coherence of a community of practice can be both a strength and a weakness" (p. 85).

\section{Negotiating the "Joint Enterprise" of Team Learning}

A major strength of the team design is its emphasis on and support for team building, or what Wenger (1998) would call community building. It also was one of the coaches' more challenging responsibilities. With coaches taking the lead, part of team building often included team members working together to determine how time in team sessions would be spent. The Handbook provided coaches with a potential session template as well as reminders for "what the team learning experience should accomplish" (p. 3). The Handbook also emphasized the idea that it is important to use the time productively and that "team members will be more committed to their teamwork if they feel their time is well spent" (p.12). The Handbook warns that building time in to cover certain things may not be popular. In Wenger's terms, defining the "joint enterprise" of the teams is a characteristic of team building and to keeping a community of practice together. Because defining the enterprise is negotiated in practice, Wenger (1998) argues that it is more than a stated goal and "is never fully determined by an outside mandate, by a prescription, or any individual participant" (p. 80). In my interviews and observations of the teams, the dynamic of negotiating the joint enterprise sometimes evolved in ways that seemed to build strong, cohesive teams but did not necessarily align with the program designers', and in some cases, coaches' vision of productive learning. 
In establishing a routine or joint enterprise, coaches sometimes felt pressure from team participants and the design of the course to emphasize more traditional approaches to covering large amounts of content, such as relying solely on lecture notes rather than completing the readings or by memorizing facts without discussion. Contexts and participants shape the environment as much as the proposal of a design, and at times, that can take the form of resistance to a more balanced blending of the acquisition of knowledge and the creation of knowledge (Wenger 1998, p. 214). For example, Molly, an experienced coach, called the sort of discussion described by Rebecca as "going off on tangents." She added, I'm not one for straying too far from the material." For Molly, the goal was to perform well on exams and sharing experiences or discussing current events in relation to the material could be interesting as a brief change of pace, but it was not a productive way to achieve the best test scores. All the coaches are excellent students, and Molly in particular was a 4.0 GPA senior. As an experienced student, Molly believed she had a clear idea of what was needed to "cover" the material ${ }^{8}$. She said, "I never felt comfortable straying from what might be on the test. We never used that time to talk about cultural events or other things that weren't a part of class. The teams would have thought I was wasting their time. It wouldn't have gone well. They learned to study for the test, and I think that was pretty valuable." Molly's observation that team members would have viewed

\footnotetext{
${ }^{8}$ Coaches use of the term and expression "cover the material" often signaled a shift from a participatory and discussion-based model of learning and seemed to align more with a traditional, lecture style delivery - a transmission of material rather than the negotiation of meaning.
} 
anything other than an emphasis on the exams as a waste of time points to Wenger's (1998) explanation that "negotiating a joint enterprise gives rise to relations of mutual accountability" (p. 81). This suggests that building time into the team routine to discuss the less popular areas of course content is much more complicated than prescribing it, and that it is an ongoing aspect of team maintenance.

Molly's emphasis on how to study for the test was not in itself a resistance to or dismissal of the study team design. In fact, strategies for test-taking are included in the Handbook. However, restricting practice and "teaching to the test" align more with the dominant model of individualized instruction rather than the social model promoted by the designers of the teams. Wenger (1998) argues that "increasingly detailed prescriptions of practice carry increasing risks of being turned around, especially when a form of institutional accountability is tied to them" (p. 233). Molly's and her team's alignment with broader institutional values also may have led to more emphasis on figuring out what would be "covered" on the exams at the expense of engaging the material in ways that might allow for new meanings to emerge. In talking with members of the teams, they were very happy with the team structure and had great admiration for Molly. In fact, Rebecca had been a member of Molly's team the year before and decided to become a coach despite their differing coaching styles.

Even when coaches actively promoted the program design, the dominance of the individualized model made achieving a focus on learning as engagement in practice versus teaching to the test a constant challenge. Doug, a new coach, also 
defined his role as keeping everyone on task and coming up with ways for the team to "cover" large amounts of material. However, he also wanted to bring additional course resources into discussion even if their connection to the exams wasn't explicit. He notes, "We would spend one day of the week going over the readings with outlines the team members created, and the other day of the week previewing the next reading assignments. We didn't start out that way. We began with mapping exercises of the material including the narratives ${ }^{9}$, which I encouraged them to read." He said he liked the way the narratives provided a balance to all the statistical information about a culture contained in the textbook. Doug explained that because there weren't any questions on the finals for the narrative readings, it became "impossible" to get the team interested in talking about them despite the Handbook's suggested strategy for incorporating the narratives into a team "session template," and finding connections among the narratives, lecture, and course textbook. In Wenger's (1998) terms, the "joint enterprise" of the team as negotiated in practice was influenced by what the team interpreted as being valued by the instructor.

Just as it is influenced by the program design, the experiences and expectations of the participants, and the structure of the course, the negotiation of the joint enterprise or routine for the teams is influenced in part by the idea that each coach brings a history of experiences to the team that shapes his or her view of what that enterprise should entail. Molly's emphasis on exam performance can be viewed as

\footnotetext{
${ }^{9}$ Course material for most sections of the course included a textbook and study guide, atlas, and literature anthology referred to as the "narratives."
} 
linked to her own emphasis on maintaining a perfect GPA. Rob, for example, said that he remembers an apprenticeship experience he had in high school where the business executive he was job shadowing was very "hands-off" and let him "work the job." Rob promotes a similar approach in the team he coaches and believes the team is at its best when he is off to the side sitting back and listening to them "do the work." Ellen, on the other hand, said that she was really bothered when a lot of times she felt "useless - that I was just sitting here and facilitating a little bit but after while they didn't need me. A couple of times I couldn't make it in because of the ice and they met on their own. Someone said, 'Oh, your team was so good they were working away.' For some reason, that really bothered me." She remembered that when she was a freshman she looked up to the students who worked in learning centers. "They were so knowledgeable, not just about their subject, but about the campus and school." For Ellen, it was important to have a recognizable role in the routine.

Examining the emergence of the joint enterprise and routine of team sessions points to the importance of an awareness of team maintenance issues, such as the competing models of learning coaches are negotiating. They are not only coaches, but also students themselves in courses across the University. As noted above, they feel accountability to participants and the institution in terms of helping students perform well on exams, which is also a response to the dominance of an individualistic model of learning in areas overlapping with the teams. Supporting study team coaches by making tacit understanding of the work of competing models of learning explicit is 
important and given the overall success of the study teams ${ }^{10}$, the shifting balance between the acquisition of knowledge and the creation of knowledge may not always be that visible.

\section{Addressing Team Issues: New Approaches to Traditional Methods}

Another area that provides a deeper understanding of team learning is in the ways coaches problem-solve issues, such as what they perceive as a lack of participation on the part of some team members. The line between being a coach and being a teacher can become blurred as they problem-solve team issues. Ellen, a veteran study team coach, said, "When you are a student, it sometimes is this-it's you versus the teacher-like you are on one side and the teacher is on the other. Being a coach sometimes puts you in this weird gray area. It has given me more insight into why professors do some of the things they do like attendance policies. Or why teachers would adjust and curve tests_-recognizing that when large numbers of students do poorly on a test there is a problem there that is both teacher and student." That "gray area" Ellen describes happens for other coaches as well. They feel this "gray area" most acutely when things seem to go wrong. Coaches feel a tremendous responsibility for the teams. If there are issues with the team, they feel students look to

\footnotetext{
${ }^{10}$ Performing well on the exams and receiving good grades for the course was certainly a goal of the teams. Overall, a higher percentage of students participating in study teams received A's and B's than those who did not, as reported by the Center. Receiving a better grade was also a recruitment strategy and reason for students to engage in team activities. Additionally, a significantly lower percentage of study team participants received F's for the course. However, grades are not always an accurate measure of learning.
} 
them to fix the problem. In this sense, the team members are also defining the role of the coach.

Just as coaches can describe what productive learning looks like, they also point to the opposite to describe frustrating moments when they feel things are going wrong - that learning, in the best sense, is no longer taking place. If successful learning in the eyes of the coaches is participation, then nonparticipation is their evidence for a lack of learning. In their view, if conversation is the key to "opening the floodgates of memory" (Rebecca's description) and new connections, then silence is refusal to engage. If regular attendance and "doing the work" is "teamwork," then absences and "not pulling your weight" is not being a "team player." Addressing those issues is some of their most challenging work in the Center.

There is plenty of educational history to backup this clear-cut assessment of a learning environment. As excellent students with plenty of classroom experience, the coaches are familiar with the ways teachers "deal" with difficult situations. All the coaches I interviewed said that after becoming study team coaches, they started paying more attention to the ways teachers managed difficult classroom situations. In the coaches' view, when things aren’t going as planned, they must assume more of a teacher role - they have to enter that "gray area" that Ellen talked about and try to enforce good student behavior. Below I examine some of the issues that coaches find most frustrating. 
What coaches described as a lack of motivation to learn the material or "buying-in" to the value of learning the material was one of the most troubling and frustrating issue identified by the coaches. For example, a new coach said she had thought about things that she would do differently, which seemed to center around having more policies and rules. She didn't want to be "seen as the big bad wolf," but she said she might consider having a policy for tardiness, turning work in on time, and absences.

Coaches talked about these issues with each other in the staff education class, and as one coach described, through the "flow of conversation in the halls and the coming and goings from the teams." Sue, for example, noted that one coach had come up with a policy part way through the semester that if a team member didn't turn in his or her work, it counted as an absence. Sue wasn't sure if she wanted to go "that far," but she felt like something needed to be done. She viewed these types of problems as a "letdown to the team," and that team members looked to her to "keep people in line and doing their fair share."

It is interesting that while the coaches were extremely creative in developing and implementing strategies for learning, they often turned first to more traditional approaches to problem-solving (what teachers do) when they felt things were not going well. For example, the Handbook offers a number of strategies for troubleshooting common team problems. Prescribing participation and reifying behavior through the addition of policies is not among them. Instead, a more social 
learning model is promoted. In the Handbook, coaches are reminded that team members need to find the meeting times useful. They are also encouraged to ask students what they are learning, what they think could be improved. They are encouraged to take roll, not as penalty but as an incentive in the form of a certificate that students can use as evidence of experience with team learning. The Handbook also suggests providing emotional support in the form of letting participants know they are needed members of the team. The strategies in the Handbook point to the idea that learning issues are not amenable to quick-fix solutions but should be addressed as part of ongoing team maintenance.

Despite the availability of strategies from the Handbook, one stumbling block to addressing issues in the teams is that it often defaults to an emphasis on individuals rather than team building. In the example from my team, I initially wanted to compare my experience with Rebecca's in terms of the range of experiences represented in the teams. Doing so, I might have drawn the conclusion that members of Rebecca's team had a broader range of experiences; however, I think it is also important to look at this example in terms of the interaction of practice and design. In the example from the team I coached, the student's narrative emerged from a routine practice of going through lecture slides. Wenger's (1998) framework might offer further insights. He argues that "learning communities will become places of identity to the extent they make trajectories possible" (p. 215). A trajectory includes a "past and a future and to strengthen an identity of participation, allowing learning community members' 
pasts - what they have done, what they know, contribute to the constitution of its practice" is important (p. 215). Looking solely at the make-up of the team could not account for how narrative evidence aligned in practice for team members.

Another alternative to focusing on individuals is considering Wenger's (1998) concept of regimes of competence. The established regimes of competence in the team I described were to value what is written down, what is "available on the Internet" over personal experience. Wenger explains that in a learning community there is a "wisdom of peripherality" which can become "easily marginalized within established regimes of competence" (p. 216). Wenger suggests there are two kinds of marginality — one of competence and one of experience and together they reflect the community identity duality. A marginality of competence represents certain members are not full participants, whereas marginality of experience can occur when certain experiences do not mesh with the learning community's regimes of competence. The goal is "turning marginalities into peripheral wisdom, which requires identities that can play with participation and non-participation" (p. 216). In contrast to Rebecca's team, the discussion of polygamy in my team remained focused on the individual experience and became an evaluation of that experience rather than creating new meanings.

Another example of the limitations of drawing on traditional "teacher approaches" to making students toe the line comes from Rob's teams. He coached two teams that he described as very different. He feels that for the highly motivated and 
participatory team he is coaching that he is learning as much from them as they are learning from each other. On the other hand, in the team where he feels the participation is quite poor, he feels he has to take on much more the role of a teacher.

To address the issue, he said he spent a good deal of time thinking about what is the difference between his two teams that makes one highly motivated and the other not, and what he could do differently. Rob used comparison and contrast as a way to analyze and address the issue. He tried a number of different criteria for his analysis. “At first, I thought maybe they don't know each other, but when I come in the room they are talking with each other and when I arrive, they stop talking-which is the same with the other team-it's time to go to work." He then compared ages between the team, but found that they were all freshman in both teams. In the "good" team, two people knew each other from before, but he dismissed that as a factor. The dynamic characteristics of team learning limited the explanatory power of comparing and contrasting team characteristics or looking for a direct cause and effect between design and practice.

Coaches who have found dramatic differences between teams have trouble using that information and criteria to solve issues. In fact, teams can be dramatically different and still function effectively_differently, but productively. In addition to the study team Handbook, how can Wenger's (1998) framework help coaches view participation differently? He argues, "In order to redirect learning, it may be necessary to offer learners alternative forms of participation that are as much a source of identity 
as they are finding elsewhere" (p. 215). Issues such as nonparticipation are opportunities for new designs and practices to emerge. Established routines may serve the joint enterprise and a majority of participants well, but as Wenger argues, even "full participants are not immune to marginal experience" (p. 216). The "wisdom of peripherality" includes "the paths not taken, connections overlooked, choices taken for granted" (p. 216). In some ways, Wenger (1998) is suggesting it is difficult to see the forest for the trees. Well-established regimes of competence marginalize other possibilities. Shaking things up as some coaches did, observing each other's teams, and other ways of interacting with each other are all ways coaches can reveal paths, connections, and choices without prescribing practice.

Focusing on a certain image of what individual participation looks like can also limit the options for addressing issues of nonparticipation. Carl described one of the teams he coached as very unproductive and not knowing how to motivate them, he turned to games as a "last resort." He said, "Playing games at least looks like everyone is participating." Carl also noted that in some ways he felt frustrated having to "constantly try to come up with something to motivate the team." As a disciplined student, it was difficult for him to understand why someone would appear to "waste his and others' time.” As discussed earlier, "mutual accountability,” a key characteristic of community coherence, is not something that Carl can enforce. It is the work of the team as a part of practice. In his observations of claims processors, Wenger (1998) noted, "Responsibility with respect to what makes life harder for 
others, for instance, is something they enforce among themselves, sometimes quite vocally, because they all understand that making their work life bearable is part of their joint enterprise" (p. 81). This suggests that on-going team building is important long before issues arise, especially because the study teams are limited to one semester of bi-weekly meetings.

It is also important to note that even though the students' roles in the teams are often discussed, prescribed, and memorialized in quotations about teamwork on the walls of the study rooms, the students are still in the process of becoming team members - they are newcomers. Also expressing frustration about a seeming lack of participation and motivation, Rob said, 'I don't know why they keep coming. They don't seem to be getting anything out of it. I suppose if they are coming they must think they are getting something out of it." In apprenticeship models, for example, full participation is the goal but it is a trajectory. Projecting an expectation of their more experienced and disciplined understandings of learning onto newcomers is not an invitation to practice.

Another roadblock to the sort of deeper learning that many of the coaches wished for and the program design promoted was the course structure. Coaches described feeling the long-arm of the instructor and structure of the course when teams pushed for more focus on memorization of quantitative data in order to perform well on exams. Doug explained that while the teams he coached were able to establish a solid routine for targeting material that would be on the exam, the routine would 
become boring after a while. He said, "The team was really good at taking a lot of material and condensing it down to main points in their outlines. But outlines can get really boring."

Attempts to radically change the joint enterprise were often met with resistance; however, shifting the emphasis from an acquisition of knowledge to the creation of knowledge in ways that offered respite from boredom and still aligned with the joint enterprise of the team were more acceptable. For example, Sue noted that students in the team she coached liked their routine of going through the notes and answering study questions and didn't want to alter it. She said she noticed that the practice of sharing notes began to change and that there was little discussion. Students were merely copying their notes and exchanging them. She believed the routine had become boring and some people were not turning in notes. She suggested the team change things up. As someone who had done a good deal of travelling and was planning to go into the Peace Corp following graduation, Sue thought it would be interesting for participants to imagine travelling to one of the regions they were studying. They discussed where they would go, what they would see, what it would look like, how it would be different from their life at school. The information was still there, but she looked for ways to make it more meaningful. Sue's awareness of changes within a practice such as exchanging notes provided an opportunity to revitalize an existing practice. She said the team started to seem more interested in their notes as a way to come up with more details for their "trips." 
Another way that coaches problem-solved the issue of boredom of routine was to develop learning games. This solution seemed to emerge through interactions among the coaches. Preparing games for the team was very time-consuming and the coaches devised ways to share. One coach created a network drive in a computer lab in the building and coaches began to save resources for each other. They also created spaces in the Writing Center where they could leave resources for each other. In the next section, I explore the coaches' development and use of games in more detail.

\section{Redesigning Practice: Playing Games and Building Community}

The practice of creating and sharing the games led to even more interaction among the coaches. Working together to create the games was different than the efforts to problem solve attendance, tardiness, and "not doing the work" issues. By that I mean games were seen as productive fun and creating them together and sharing the resources was very positive. Discussion of the motivation issues was often negative, a time when coaches, although deeply concerned for the students, needed to blow off some steam. In a staff education class discussion of that topic, one softspoken coach said, "Sometimes I have to be mean." The shock for her of that admission was felt by other coaches as well. Coaches often feel that they are responsible for maintaining a high level of "teamwork" in the teams. When things don't go well, it seems common for coaches to quickly abandon a peer-learning model and assume what they view as a more teacher-driven model. They want to adopt policies or rules that serve to "enforce" learning and yet, learning cannot be enforced. 
Instead of adopting a negative model, one that makes them uncomfortable, what if they analyzed positive models of participation? For example, their own highly engaged participation in the work of the Writing Center offers three key elements of inviting participation: 1) they have a say in the design and structure of the work, 2) they contribute in significant ways to the shared tasks, and 3) they have time and support to reach full participation.

Not all the coaches or team participants were in favor of playing the learning games, and in some cases, it could be argued that the games relied on rote memorization or the decontextualizing of content. However, given the opportunity to talk about the games and develop them in a supportive environment, in most case the coaches' creative use of the games demonstrated a sophisticated understanding of learning beyond memorizing concepts. Doug explained that he brought in games at first as a way to "lighten things up and have a bit of fun." He said he realized later that using games like Pictionary and Taboo as models for study guides was a really good way for them to have built-in techniques for remembering things for the test. It brought in a different learning style and gave them a visual image of a concept." He remembered a student say that when she was taking the test and came to a question about one concept in particular, she remembered what it "looked like," and he saw that as confirmation that things were working well. Doug also began to analyze and think about the ways one game may work or "feed into" another game. For example, he 
noted that Pictionary provided a visual component while Taboo was focused on using language to understand a concept.

The coaches also used games to provide different forms of participation. Rob noted that his reason for playing games wasn't necessarily memorization. Instead, he hoped that when a word or concept worked through in a game appeared on an exam, it would jog a memory of their conversation. This type of work can also help in terms of team-building. When team members make these connections, the team is viewed as valuable. As with Rebecca's adjustment to the joint enterprise of the team in an earlier example, changing the routine due to perceived boredom offers an opening for changed practice and also provides a point of reflection for a richer understanding of the teams. Another advantage of creating the games is that it brings coaches together in new configurations. Sitting around a table cutting up scrap paper for Jeopardy questions provided an opportunity for other topics to emerge.

Thinking of study teams as dynamic learning communities may suggest alternative ways to view issues in the teams. Reifying attendance through a policy does not ensure participation. As Wenger argues, reification has to be adopted by a community before it can shape practice in significant ways. It isn't that it might not be necessary to impose some order through negotiation, but that there should be a balance between reification and participation. At the same time, how can the program design help coaches feel less like teachers when they need to address issues and to draw more 
from their experiences as members of other communities of practice, the Writing Center in particular?

\section{Newcomers and Old-Timers: Developing a Sense of Belonging}

Immersion in the Writing Center community of practice is a valuable model

for the sort of team building the program design promotes. In other words, the conditions that support new coaches' growing participation in the Writing Center on some level of scale also apply to the study team participants. As leaders of the teams, coaches are an embodiment of the Center and a proposal of an identity for team participants. New coaches emerged from the teams, following what Wenger refers to as a learning trajectory. For example, Melinda, a team member in Rob's team, said she admired him as a team leader, student, and "just thought he was a really neat person." She wanted to become a coach as well. As a newcomer, she said the collaboration of the coaches is important to her. "When I use the resources, I am basically learning from all the coaches before me, even those who are no longer here. They passed down their experiences in the form of the resources. Now, when I use the resources and add to them, I am passing down what I have learned."

As an "old-timer" Rob said he viewed himself as a role model for other coaches, but he said he was of two minds about formally assigning mentors. He said, "Coach training mentors are both positive and negative. Yes, it would be beneficial to have someone help get you started and be a sounding board for issues and suggestions for what to do." At the same time, he noted that could also mean that the newcomer 
could simply do what the other person did rather than discovering something new and adding to the knowledge base. Rob's insights suggest that more and varied interaction with veteran coaches is an important consideration.

As resources for each other, the coaches looked for ways to find time to work together and discuss the teams. Often in writing centers, especially large centers, coaches will get to know the other coaches whose shifts they share and through professional development activities. Because of the coaches desire for more interaction the Center developed the practice of allowing coaches who coached teams in the same section of the course to work together during the coach class and to connect with each other regularly via email. In many ways, this contributed to the high standards coaches held for their work. Sue said she was very impressed by the level of commitment and creativity of the veteran coaches. "They were so enthusiastic, and I brought that enthusiasm to my team. I admired the way they were creating scavenger hunts, Jeopardy games, and other activities. For me, the best parts of the class [staff education] were the break-out sessions with the veteran coaches.

Working with old-timers also helped newcomers challenge some initial concerns and assumptions about learning. Both Sue and Doug had concerns as new coaches that the students in the teams wouldn't "respect" them because they didn't take the course - that they wouldn't have an expected knowledge. Doug said it was helpful to have had a semester working with other coaches who had coached teams for the same instructor. He told his team that "he was surrounded by others who had had 
the course and had coached teams for the same instructor." While this type of "insider" information can be useful, it also may focus the teams too much on secondguessing teacher expectations at the expense of engaging the material in more meaningful ways.

As part of the ecology of the teams, ignoring the course goals and teacher expectations is also inappropriate. As newcomers Doug and Sue gained more experience, they became more confident about trying new practices. For example, they invited the instructor to visit the team—on the team's turf, so to speak. Both coaches and students reported that they liked having the instructors see them "at work." Instructors also welcomed the opportunity to learn more about the teams. Another practice is to invite the instructors as a group to the Center at the beginning of the semester for a presentation by the coaches about the study teams. They also are given the opportunity to talk about their course. These approaches recognize the separate but overlapping communities at work.

Listening to the coach voices I see the work of engagement: students developing relationships, participating in a common enterprise, interacting with their coach — an "old-timer." I see a willingness to take risks, play, and the possibilities for the work of imagination. The work of alignment can be seen in the coaches' alignment with the values of the Center, and in team participants who chose to become coaches. In the next chapter, I look more closely at Rebecca's experiences through the lens of engagement, imagination, and alignment. 
While the study teams or even the Writing Center coaches may not constitute a community of practice in the same sense as Wenger's (1998) claims processors do with their longer-term relationships negotiating a joint enterprise, one can argue that they are a type of learning community and understanding the work of engagement, imagination, and alignment helps the designers of these contexts support and cultivate learning that leads to new identities. Wenger's concepts are also useful to helping coaches not only discuss the theory of learning that informs their work, but also as an alternative model for the learning issues and competing ideologies they encounter. 


\section{Chapter 4}

\section{The Work of Belonging: Learning Shaping Coaches}

In the previous chapter, I explored how the social theory of learning informing the study teams is enacted by the coaches and team participants through the activities and practices of the teams and as they negotiate learning issues, such as motivation. Based on my interviews with coaches, team participants, and observations of the teams, I concluded that the Writing Center's core values and design for team learning was taken up by the teams in both predictable and unpredictable ways. Wenger's (1998) argument that design is only one of the resources for learning was illustrated by the emergent interpretations and practices enacted by the teams. It was also evident when competing ideologies and traditional models of learning became a point of tension and negotiation within the teams. Making visible these aspects of team learning is an important step in working against ideologies that define literacy as merely a measurable technical skill and peer learning as indoctrination into a particular kind of discourse and a particular way of thinking. Another important step toward this end and the focus of my data analysis in this chapter is a deeper understanding of the work of identity in a social model of learning.

\section{A Coach Case Study: Opening New Identities of Participation}

I narrow the focus in this chapter to one coach and argue that not only is the work and type of learning promoted by the study team design a complex negotiation of varied resources for learning, it is the type of learning that moves beyond simply 
designing spaces for learning course content—it proposes the possibility of new identities - what Wenger (1998) suggests is the essence of education (p. 263). In other words, the social model of learning enacted by the study teams is not a dismissal of content. In the teams, content is one of the resources for structuring the social interactions that are important to learning. In this sense, when designers of learning contexts or curriculums attend to the work of identity it is never at the expense of attention to content. Instead, a social model of learning emphasizes an awareness of and support for the emergent quality of learning - the unpredictable connections that are made when learners are engaged in any learning context.

To further explicate this type of learning context, I draw on Wenger's (1998) models of belonging: engagement, imagination, and alignment to frame my case study of one coach. As noted in previous chapters, Wenger argues that "talking about learning in terms of these modes of belonging makes it possible to consider educational designs not just in terms of the delivery of a curriculum, but more generally in terms of their effects on the formation of identities" (p. 271). For learning to lead to identity formation, Wenger notes that students need

1) "places of engagement

2) materials and experiences with which to build an image of the world and themselves

3) ways of having an effect on the world and making their actions matter." (p. 271) 
I chose Rebecca (a pseudonym) for this case study because I had the opportunity to observe, work, and interact with her in the Michigan Tech Writing Center throughout her undergraduate career. As a freshman, she was a team participant and after that experience Rebecca applied for a position and was hired as a Writing Center coach. I follow her experiences and evolving identities as she becomes a study team leader and develops goals for her future. In my interviews with Rebecca, she discussed her own learning experiences as well as how those experiences have shaped not only her goals but also the changes she believes are needed to make learning more meaningful for students. I think her experiences offer insights into the ways writing centers and other learning communities can better support learning and create rich learning environments that are more aligned with social theories of learning and literacy. Educators should listen to what students like Rebecca have to say. Further, not all peer tutors find their experiences as meaningful as Rebecca's, and my decision to examine her experiences is not an attempt to argue that they do. Instead, I argue that the work of engagement, imagination, and alignment can also provide insight into why a particular context for learning is not supporting those kinds of meaningful experiences.

\section{Extending the Reach of Peer Learning: Something More than "Helping Others"}

Like other students who have worked in writing centers, Rebecca found her work meaningful and deeply connected to other areas of her life. That working in a writing center is a valuable learning experience has been argued by Brad Hughes, 
Paula Gillespie, and Harvey Kail (2010). Through their Peer Writing Tutor Alumni Research Project (PWTARP), they document the learning experiences of 126 former peer tutors from three institutions. They argue that in addition to becoming better writers, peer tutors "develop in a number of other highly consequential ways: as thinkers, as writers, and developing professionals" (p. 13). One of the key findings of the study was that peer tutors reported a "deeper understanding of and commitment to collaborative learning" (p. 24). The authors cite Bruffee's (1978) model of collaborative learning and liberal education. They argue that one reason peer tutors are drawn to the collaborative model is that they see that "'they can help other students become better writers" (p. 36). They also note, "peer tutors take on an agency that's often lacking in their own classroom learning and in peer-review sessions" (p. 36). While their findings are important, the primary emphasis is still on the power of "individualized conversation with a succession of individual students" (p. 37). Rebecca's experiences and insights help to demonstrate that this type of work and learning is even more valuable than their findings suggest.

The notion of helping other students become better writers is a limited model of writing center work-it's more than that. Literacy, as Brian Street $(1995,2001)$ has argued, is always ideological. As Rebecca's experiences will demonstrate, peer tutors can also challenge dominant world-views and support learning more broadly across the University. Attending to the identity work of engagement, imagination, and alignment can cultivate this type of peer learning model. 


\section{Learning Trajectories as a Focus of Study}

By analyzing interview data from Rebecca, I will examine her learning trajectory, particularly her evolution from a Writing Center newcomer to what Wenger (1998) calls an "old-timer." He argues that a "community of practice is a field of possible trajectories and thus the proposal of an identity" (p. 156). As newcomers interact with old-timers, "they can engage with their own future, as embodied by oldtimers" (p. 156). I also draw on Rebecca's connection of her experiences in the Writing Center with other learning experiences as she pursues her chemical engineering degree, applies for an internship in an immunology lab, travels to conferences, and discusses her desire to go to graduate school for a $\mathrm{PhD}$ in immunology. This is important because a more longitudinal view of student learning, ${ }^{11}$ one that also accounts for multiple and overlapping forms of participation (i.e. the Writing Center, the classroom, and conferences) may reveal important aspects of learning. For example, it might provide insights into what students find truly valuable and relevant to their education. Students are regularly asked to assess their learning at the end of each course; however, those types of assessment of student learning cannot account for the impact of learning experiences outside the classroom such as participating in a community of practice like a writing center. Nor can they account for the cumulative effect of a variety of learning experiences over time. Even

\footnotetext{
${ }^{11}$ For example, Marilyn S. Sternglass's (1997) Time to Know Them: A Longitudinal Study of Writing and Learning at the College Level, in part draws on case studies to examine students' development throughout their college experience.
} 
learning assessment tools that rely on longitudinal data like the College Learning Assessment $\mathrm{CLA}^{12}$ may assess a longer period in students' learning experiences, but they are narrowly focused on what they view as discrete sets of skills, which further works to institutionalize an autonomous view of literacy (Street 1995, 2001).

Understanding more about coaches' learning experiences is also important not only to creating a supportive learning ecology in writing centers but also to developing more meaningful learning experiences for students across the university and for rethinking students' contribution to the teaching mission of the university. Wenger (1998) argues that "in terms of forming identities of participation, the organization of schooling tends to offer students very limited contacts with adulthood as a lived identity" (p. 276). Working from a social model of learning, the director of the Michigan Tech Writing Center purposely created opportunities for coaches to interact with each other, the director and other permanent staff, and faculty teaching the course. For example, study team coaches like Rebecca actively participated in ongoing discussions of team learning and design during the weekly staff education meetings. They were given opportunities to work together and share strategies in informal and formal settings, attend writing center conferences, and they also were

\footnotetext{
${ }^{12}$ See footnote one in Chapter 1 for a more detailed explanation of the CLA. As noted in that chapter, part of the argument for those who challenge peer learning (2011, Arum and Roksa) is that there is little evidence to support peer learning other than benefits to "socialization," suggesting that as an assessment tool the CLA did not fully account for experiences outside the classroom as potential and legitimate sites for learning. It also promotes a dismissal of the importance of social interactions and relationships as part of a learning community.
} 
invited to share their insights with faculty teaching the course. As part of staff education, coaches read from a variety of disciplines and discussed ways other perspectives might inform practice. This type of participation is a good example of the ways coaches, as study team leaders, are given access to new practices and forms of participation that shape their own and others learning trajectories.

\section{Rebecca's Story: The Process of Becoming a Writing Center Coach}

Rebecca is one of many former study team participants who became a Writing Center coach following that experience. She describes her study team's coach as "being confident about herself" and "being able to talk with anyone." She also admired the coach's "leadership qualities." Nearing graduation, Rebecca returns to that early "proposal of an identity" when she writes, "I never liked being in the lead before I started working in the Writing Center because I was always scared of the responsibility. The Writing Center helped me to become a responsible leader. I feel comfortable with my decisions, my opinions, my suggestions, and my thoughts. I am willing to take responsibility for myself when I am in the lead now because I am confident that I am a good leader.”

Leadership, change, and diversity were recurring themes in my conversations with Rebecca, and each of these concepts serves to frame her evolving identities from study team participant to study team leader, but also as she negotiated other identities as a chemical engineering major and International Graduate Teaching Assistant Program coach. In terms of leadership, Rebecca's experience and understanding of 
what it means to be a "good leader" is different than typical definitions found in educational settings. Wenger (1998) describes a leader as someone "who can expand the potential of negotiability for other participants in a community of practice" ( $p$. 296). Rather than looking for ways to enforce certain attitudes toward learning, study team coaches like Rebecca lead by finding ways for students to engage in work they find valuable and connected to the purposes of their lives, thereby expanding the knowledge of the community of learners as a whole. For example, as noted in the last chapter, Rebecca was particularly adept at leading discussions and taking advantage of encouraging multiple perspectives to surface and be considered.

In Rebecca's own words, "My work in the Writing Center has essentially connected to all the other work I've done at MTU because it has changed me as a person." The type of "change" Rebecca is referring to is different from the ways it is often viewed in writing centers and composition classrooms. Often in the name of "higher order skills" or "critical thinking" students are not only asked by academics to "become more like us" but at the same time leave behind other aspects of their identity (Grimm 2011). Grimm's analysis points to type of change advocated by Bruffee's (1984, "Peer Tutoring") highly influential model of peer tutoring. For example, unlike Rebecca's leadership style described above, many group learning contexts work to achieve consensus, which not only limits participation, but often works toward an artificial guessing game as to the teacher's already established (and tacit) position. In contrast, the type of "change" and learning experiences Rebecca refers to allowed her 
to draw meaningful connections between her own past experiences, her work in the Writing Center, and her chosen field of study.

One key to Rebecca's ability to engage students is her appreciation for diversity, a core value of the Center. She writes, "Probably the most important way in which working in the Writing Center has affected me in other areas is in the acceptance of diversity. Since I started coaching in the Writing Center I've become so much more aware of the benefits of diversity on campus." The promotion of diversity as a value on many campuses and programs is common; however, educators need to ask why do some types of programs often seem to fall short of their goals? For example, many programs feature one-time opportunities to "celebrate" diversity, which aren't without value, but what is needed is more sustained authentic practice in negotiating and communicating in diverse environments such as Rebecca experienced. When diversity is a resource for learning, its success isn't measured in an individual student like Rebecca saying that she has come to appreciate and accept diversity. It is how she is able to put that core value into practice.

As I noted in the last chapter, Rebecca demonstrated her ability to enact that core value through the conversations she fostered in study teams. Her leadership of a conversation about the Middle East conflict, for example, resulted in American and International students rethinking their assumptions about culture - their own and others. In the next section, I use Wenger's modes of belonging to further explore the connections Rebecca makes to leadership, change, and diversity and as a framework 
for understanding the work of a social theory of learning within a community of practice.

\section{The Work of Belonging: Engagement, Imagination, Alignment and the Formation of Identity}

Rebecca's embracing of new identities and identification with leadership and diversity as the most important aspects of her Writing Center experience isn't happenstance or simply an end result of her individual drive and determination to succeed. Rebecca saw herself as connected to the work of the Writing Center in meaningful ways because the designers for learning in this context (the director and other permanent staff) extended opportunities for participation and engagement in the practices of the Writing Center, including opportunities for coaches to contribute as designers themselves. For example, coaches were given a good deal of autonomy and voice in how the study teams were designed. As Wenger (1998) argues, making practices available to newcomers and providing opportunities for newcomers to interact with more experienced practitioners is essential to learning.

Extending membership and opportunities for varied forms of legitimate peripheral and full participation is important and requires a re-imagining of how sites for learning such as writing centers are designed. Rebecca's conviction that her work in the Writing Center has "changed her as a person" clearly suggests that to re-imagine learning, one must consider the work of identity. Wenger's (1998) modes of belonging are a way to understand identity formation within a community of practice. In this view, the focus is on the individual but from a social rather than individualistic 
perspective. His concepts help me think about the value of learning experiences coaches gain from their work in the writing center and the ways writing centers can work to support and design for these meaningful work and learning experiences.

Wenger's emphasis on communities of practice provides an alternative to individualistic models of learning that still inform many writing center staff education handbooks. For example, two of the more popular handbooks for staff education are The Bedford Guide for Writing Tutors in its fifth edition and The Allyn and Bacon Guide to Peer Tutoring in its second edition. Neither guide discusses group tutorials and focuses exclusively on a one-to-one tutoring model that emphasizes a focus on higher order writing issues. The emphasis on helping a particular kind of writer-the writer with anxiety, the writer with basic skills, the ESL writer-shifts the focus away from creating a learning community. As Wenger (1998) notes, a community of practice is not necessarily a learning community, and his framework provides a way to determine how the community of practice is constituted.

The modes of belonging (engagement, imagination, and alignment) are critical to a community of practice becoming a learning community. In brief, engagement refers to the active involvement in the practices of a community; imagination is a matter of seeing a role or trajectory for oneself in a community; and alignment is believing in the work of a community. In terms of community building, Wenger (1998) argues that each mode requires different kinds of "work" (p. 184). For example, giving coaches access to participation in the practices of the Center as well 
as the ability to affect change in those practices is one aspect of the work of engagement. Imagination requires a certain amount of "playfulness" and "taking risks" (p. 185). Creating new ways for coaches to interact with one another, to share stories, to try new ways of doing things, and to see themselves in others are important to supporting the work of imagination. Wenger argues that the work of alignment "requires the ability to communicate purpose, needs, methods, and criteria" (p. 185). Encouraging coaches to present at writing center conferences as a part of practice supports the work of alignment as does involving coaches in presentations on campus, such as events for stakeholders in the study teams (faculty and administrators).

As I argue in previous chapters, the modes of belonging can reveal aspects of the learning ecology; however, how they work together over time and are in tension also is important to pay attention to. It is also important to keep in mind that as a learning ecology, the space of a Writing Center is one aspect of an open system. What happens at the boundaries - where classrooms, administrative units, departments, and the Writing Center overlap are also considerations in designing for the support of engagement, imagination, and alignment. Next, I use Rebecca's experiences to further explicate Wenger's modes of belonging and the conditions that best support the type of learning leading to the "opening of new identities." 


\section{The Work of Engagement}

As a freshman, Rebecca described herself as "nerdy" and was motivated, in part, to join a Michigan Tech Writing Center World Cultures study team to maintain good grades. She noted that when she took the class, "it was hard for me to understand how to take in and keep up with such a large amount of information." Rebecca also said that she enjoyed the class and the instructor - that "not everyone is as nerdy as me, but I enjoyed the movies and the plays." As the semester progressed, Rebecca's "nerdiness" shaped the practices of the team and her own understanding of how to "deal with the material." Describing Rebecca's participation in the team sessions, the coach facilitator said, "She led the team, she had all the work done, she knew tidbits about the areas we were studying. I'm not one to go on tangents and stray from the material, but she knew stuff. She got people excited." The study team provided Rebecca with a way to view the large amount of material as something to share rather than simply "deal with" and through group discussion of the material the team opened new ways to engage and participate in the course. Instead of feeling overwhelmed by the material, participating in the team provided a way for Rebecca to organize what she knew and what she was learning around an identity of leadership.

By the end of her semester as a team participant, Rebecca had decided that coaching a team herself was something that she wanted to do. Her engagement in the practices of the Writing Center followed a similar trajectory to that of her team participation. Beginning as a newcomer to writing center work, Rebecca relied on 
previous experiences and the support of old-timers as she took up and helped to shape the Center's educational agenda. She noted, "The coaches have a lot of influence over the direction of the Writing Center. A group of the most senior coaches (TAs) meet once a week with [director and staff] to plan the next week's coach meeting. Therefore, the training and support that the coaches receive is often based directly on the recommendations of the TAs, who are also coaches in the thick of it."

Rebecca's engagement and participation in the work of the Center was made more meaningful by her perception that what she and other coaches had to say mattered and could be seen in policies, structure, and values. "The [director and staff] are very sensitive to the requests, needs, concerns, and comments made by the coaches during the meetings. They are constantly taking notes, and it's quite obvious that they take them to heart. During the meetings, ideas often come up for new resources or systems and these suggestions are almost always carried through, developed, and implemented," she said.

Legitimate and peripheral participation (Lave and Wenger 1991, and Wenger 1998 ) is a key to engagement. It stipulates that learners must have access to a variety of practices and forms of participation as they move from "newcomers" to "oldtimers" in a community of practice. Rebecca was able to recount a number of ways the coaches participated in the work of the center. Pointing to activities in the coach education course, she also noted, "The reflections or journal writing are also important ways in which the coaches influence the Writing Center. Every week, they [director 
and staff], and the TAs read the reflections or journals, comment on them, and then take what they read with them to the TA meetings where they discuss ways to address coach concerns." Reflective writing is a common practice for teachers wanting individual learners to contemplate a process or personal response to a text or issue. For example, in my own classes, I have asked students to include a reflective letter that addresses certain aspects of completing a draft. In a similar way writing center staff education courses often require reflective journaling for new peer tutors. In a writing center, peer tutors also may be asked to reflect on a difficult session. In both these cases, the emphasis is on the individual learner and the audience for the journal is most often the teacher/director. What is less common is for the journals to have a broader audience and serve as a form of engagement and structuring resource for the Writing Center in the ways that Rebecca describes and is obviously aware of. As a newcomer, Rebecca was able to see herself as a contributor to the design of the Writing Center through the practice of journaling.

Rebecca's description of the ways coaches participate suggests that coach participation in the operations and policies of the Writing Center was expected - the work of engagement was built into the routine and design. She added, "Feedback is also almost always requested at the meetings and reviewed later and used to plan meetings in the future. I think the coaches really are the driving force behind any and all changes made in the Writing Center." Being heard and affecting change in a learning community are important aspects of engagement for newcomers and old- 
timers. Rebecca noted, "There are a lot of ways that the coaches can have a say, and it doesn't take long for the coaches to become aware of the many channels of communication they have open to them." Because of the dynamic aspects of a learning community, some of the channels of communication that Rebecca refers to may be emergent and not predicted by the designers. This is important to a community of practice to not only keeping learners engaged, but also to constantly creating new practices and extending the practice of the community.

\section{The Work of Imagination}

To feel connected to a community of practice, Wenger argues that a learner must be able to imagine herself participating in new ways within a community of practice. For example, in an earlier example of Rebecca's first experience as a team member, Rebecca saw herself as a "nerdy" student overwhelmed with the amount of material required for the course. As she become more and more engaged in the practices of the team, she began to see the possibility of an identity of leadership for herself. In a similar way, she was able to imagine herself as a coach through her admiration of the coach facilitator, but also through the encouragement of that coach. In Wenger's terms, the coach was in fact an embodied proposal of a trajectory for Rebecca - one where she could imagine herself becoming a coach. In the words of that coach, "She [Rebecca] had the personality of a good coach." Qualities that were once described by Rebecca as "nerdiness" were seen by the coach as leadership and knowledge that contributed to the team in meaningful ways. 
While excited to be a coach, Rebecca reported that she was nervous about coaching a study team. "I was worried that my whole group wouldn't like me, and it might be me against the group," she said. Rebecca said she turned to her former coach and other coaches for support and advice. One coach suggested she take advantage of other coaching opportunities in the Center, for example, working with a program for international graduate teaching assistants and becoming comfortable with accented English. She suggested this would help Rebecca be more aware of and take advantage of the diversity in the teams - something Rebecca worked hard to put into practice for the remainder of her time as a coach. This suggests that the interaction of newcomers and old-timers is extremely important. It also suggests that when participation is not limited or bounded by too many policies or prescribed methods, creative use of available resources can emerge.

The work of imagination extends beyond the ways members of a community imagine a trajectory for themselves within that community. It also includes the ways they imagine their membership in one community opening opportunities for membership in new communities of practice. As an open system, writing centers overlap with other areas within (and outside) the university. Rebecca's experiences outside the Writing Center emphasize the idea that the work of imagination extends beyond the bounded nature of engagement in the practices of the Center. It also suggests that supporting imagination also means that directors need to advocate for 
learning beyond the Center. Rebecca describes an important experience outside the Center this way,

I was pretty set on continuing down [MTU's] immunology track of infectious disease. However, when I was in my interview with the admissions committee, they asked about my work in the Writing Center and suddenly this whole new door opened up for me. Someone on the committee said that it sounded to him like epidemiology and the study of the way diseases move through a population might be a good fit for me because of my appreciation for culture and my ability to communicate with people ... YES!!! First of all, it was amazing to me that they had so quickly picked up on what we are all about in the Writing Center in the five short minutes I had been talking about it. Plus, I was just amazed at that connection. I hadn't made the connection before that moment, but the way diseases move through a population is completely cultural. The way people live, the food they eat, the way they interact, everything cultural effects the way diseases will spread and that is what I want to study.

Rebecca's insights into the connection between her work in the Writing Center and her chosen field of study is significant in a number of ways. First, to this point I've focused on Rebecca's experiences as a single trajectory_-becoming a Writing Center coach. In fact, the Writing Center learning community is only one of the communities to which Rebecca belongs. Wenger (1998) argues that learners have 
multiple learning trajectories that must be "reconciled" and the "work of reconciliation may be learners most significant challenge" (p. 160). If reconciling multiple learning trajectories and memberships is the most significant challenge for learners, then this suggests that helping students negotiate this work should be an important goal of institutions, but it is one that is often overlooked. For Rebecca, the connection of these two learning trajectories was significant, perhaps the most significant connection of her education to that point.

The work of imagination and reconciliation described above also suggests that the boundary crossing of Writing Center coaches can help directors to better understand the ways the Center's core values are enacted in practice. For example, Rebecca said, "The Writing Center has definitely helped me see the issue [the spread of disease] globally and culturally rather than just in a petri dish and that's the direction I want to take when I study. The Writing Center opened up a path of study for me that I could never have dreamed existed without it.” Rebecca's assertion indicates that diversity is a core value of the Michigan Tech Writing Center. Without opportunities to engage in practices that view diversity as a productive resource for learning, it would be difficult for Rebecca to imagine diversity as a key to her own learning.

\section{The Work of Alignment}

As Rebecca moved from newcomer to old-timer in the Writing Center a deepening commitment to the values and practices of the Writing Center can be seen. 
For example as she said, "I've realized that learning centers in general are an absolutely fantastic idea ... peer coaching is extraordinary. It can be hard to articulate a question to a professor during office hours because you might be nervous and professors are intimidating, but when you sit down with a coach, you don't have to have a pre-formed question in your head. You and your coach can talk through a problem at the level of peers. That kind of assistance is invaluable. I've become a huge advocate for this type of learning, and I never ever miss a chance to talk about it. People probably get sick of hearing about the amazing MTU learning centers from me all the time, but I really believe it, and I try to get people to use them whenever I can." Rebecca's ability to articulate what is valuable about writing center work is a result of the multiple ways she was able to participate in the work of the Center. Making the "why" of practices explicit through coach education, interaction with oldtimers, and the opportunity to reflect on one's work, leads to understanding whereas, lock-step methodologies and orthodoxies do not.

Processes that Wenger (1998) identifies as part of the work of alignment include, "imposing one's view, using power and authority, convincing, inspiring, and uniting" (p. 186). In this sense, alignment can be empowering. Rebecca's belief in peer learning and writing center values motivated her to advocate on behalf of students across the university. She noted that "learning center coaches, and in particular Writing Center coaches are well-respected and influential ... amongst fellow students and faculty. Coaches are likely to stick up for diversity amongst their peers and to be 
leaders on campus. We advocate for the learning centers, promoting their use, and thus contribute to the retention of students on campus. Writing Center coaches are well spoken and often in the public eye making a good impression on the university." This is a good example of the ways engagement, imagination, and alignment work together in terms of identity formation. Rebecca's engagement in the Writing Center community of practice and her alignment with its values allowed her to imagine ways she could make a difference across the university. This type of blending of the modes of belonging is important not just to Rebecca's identity formation but also to the Writing Center as a learning community. When newcomers and old-timers imagine themselves in new ways, and advocate for learning centers and diversity as Rebecca did, the work of the Writing Center is expanded.

Alignment with one community can sometimes strengthen alignments with other communities. For example, Rebecca also feels a strong commitment to other learning centers on campus. She said, "Learning center coaches are valuable because they are a direct link from students. As students themselves, they don't have the biases that faculty would and as observers of many different students, coaches would be able to provide a fairly well-balanced account of what the student body as a whole is feeling." Rebecca's insight is an important one and one that is often overlooked because students are often viewed as perennial newcomers and given limited access to legitimate participation in the practices of a learning community. In fact, students like the Writing Center coaches do serious work and should be taken seriously. 
At the same time, alignment with one community can cause tension with another community. Rebecca at times found herself clearly frustrated with the University administration. She said, "MTU proclaims to be a student centered campus. If this were truly a mission of the university, personally, I often doubt that it is . . [making the \$ sign with her hand as she spoke] the administration's best bet for getting an accurate view of student opinions, needs, and thoughts would be through learning center coaches." Another example of this type of work can be seen in the workshops and presentations on listening to and understanding accented English that Rebecca and other Writing Center coaches helped to develop. Rebecca noted that she "hates it" when students complain about the speaking skills of their international TAs and professors. She said, "I'm positive that students in the Chemistry Department hate having ... me in their classes because I do not tolerate people making fun of accents or whining about how they can't understand.” Because chemistry is Rebecca's major, her alignment with Writing Center values puts her in tension with her peer group in her chosen field of study, but this work allows both communities to re-imagine themselves. This is another good example of the ways identities of belonging can have a powerful impact on the work of a community of learning, especially as learners work to make multiple memberships coexist.

The work of alignment extends beyond the University with presentations at state and regional conferences. At the Michigan Tech Writing Center, attending and presenting at conferences for both newcomers and old-timers is encouraged and 
supported as part of the design of the Center's practice. For example, funding was provided for students to attend regional writing center conferences, and coaches and staff routinely collaborated on developing proposals and presentations. Rebecca was one of several coaches who regularly represented the Center at conferences.

Alignment is a way of seeing oneself in relation to another community. For newcomers, attending conferences can be an eye-opening experience. It is often a shock to learn that not all writing centers are the same. In her final semester at MTU, Rebecca had become a well-seasoned conference presenter. Referring to her last conference she said, “At conferences Michigan Tech makes a really good impression on other schools. Because we are such good communicators, we are effective at getting our point across to other writing centers, and I think that people paid attention to what we had to say. Our methods are unique, and far superior to any minimalist, non-direct approach, and I think we made a strong case at the last conference." She went on to say, "Even if other writing centers don't change significantly to be like ours, I feel like we at the very least gave people some ideas and most importantly, we made Michigan Tech look good to other universities. The more conferences we go to, the better because we have good ideas to share." Rebecca demonstrates a sophisticated understanding of the learning models that inform her own Center and others. At this particular conference, she presented with other MTU coaches who lead study teams and conversation groups for international graduate teaching assistants as part of their Writing Center work. Because the Writing Center design was open to discussion and 
change, coaches were able to juxtapose models of learning in ways they viewed as valuable. Their participation led them to dismiss the so-called "minimalist" model of peer tutoring (1991 Brooks), which has reached the status of writing center orthodoxy. They came to view a minimalist, non-direct (the student should do all the work) method of tutoring as unethical and were eager to share their conclusion with other centers that withholding important information is not only a detriment to learning, it can be a form of gate-keeping.

\section{Implications of Rebecca's Experiences}

Rebecca's experiences suggest that the work of providing the type of learning experiences that led to her growth begins with providing newcomers with opportunities to engage in authentic practice, access and interactions with old-timers, and a legitimate role in decision-making. It also takes community building and ongoing maintenance of the community. Best practices cannot be mandated through policy but should be incorporated as part of a flexible design that is dynamic and responsive to members of the community. In Rebecca's words, "There's no way to really be trained or fully prepared for a job like coaching, and the community of coaches that are there to help each other provide the support necessary to succeed."

Rebecca's experiences also point to key features of the Center's program architecture that are significant to designs that incorporate identity as a primary aspect of learning. I return to the beginning of the chapter where I noted Wenger's (1998) three aspects of learning that lead to identity formation: "places of engagement; 
materials and experiences with which to build an image of the world and themselves; and ways of having an effect on the world and making their actions matter" (p. 271).

As a place of engagement, the Center offers multiple forms of participation for both students using its services and coaches. The study teams offer students not only places where they can further explore course content but also a space where new learning trajectories such as becoming a coach themselves are embodied in their coach facilitator. The Center also offers space for the type of interactions students don't generally find in traditional classroom settings. For example, they have opportunities to interact with a much broader range of students and to interact with instructors and administrators as practitioners in a joint enterprise.

Rebecca was able to build an image of the world through her identification with the Center's core values and the opportunities she was given to explore those values in practice. Maintaining the significance of core values to the Center in practice is difficult on-going work. As an element of the Center's architecture, core values are reflected in hiring practices, reports, even the Center décor, and in how it works to create a particular public and internal image of itself.

Many aspects of Rebecca's experiences as a coach point to the importance of the coaches' contribution to the Center. She emphasized that having a role in important decision-making and day-to-day operations of Center was something lacking in her other educational experiences. As part of the architecture of the Center, coaches are an important resource for developing and maintaining best practices. In 
122

the final chapter, I illustrate how the architecture of the Center is an on-going process of the planned and emergent. 


\section{Chapter 5}

\section{Supporting the Work of Belonging}

The conclusions drawn from this research suggest that designing learning contexts that cultivate and support the formation of new identities is complex, involves a flexible and opportunistic design structure, and requires the availability of multiple forms of participation and connections across contexts. Further, the type of learning emerging from these designs provides an alternative to traditional models of peer learning, one that has significance for both writing centers and education in general. Additionally, the findings of this study point to the limitations of more traditional forms of curriculum design and assessment for uncovering the relationship of identity formation to learning. To make the work of identity visible and a primary feature of learning, a different design framework is needed.

Throughout this dissertation, I have drawn on Wenger's (1998) modes of belonging as a method of analysis. I have argued that his framework not only serves as a method for investigating the study teams, but it also defines the learning theory informing the Center's practices and design for the teams. As design components, engagement, imagination, and alignment cultivate and support certain practices and offer the flexibility for new practices and forms of participation to emerge. In this final chapter, I identify key design features associated with each component and apply them to writing center contexts. 
While these design features can be viewed as recommendations for developing and supporting a context for learning, it is important to recognize that this is not a lock-step model designed to institutionalize a particular curriculum. As Wenger (1998) argues, educational design "cannot be a closed system that shelters a well-engineered but self-contained learning process. On the contrary, it must aim to offer dense connections to communities outside its setting" (p. 275). In the examples from my study, coaches and students in the study teams found their experiences most meaningful when they could connect those experiences with other experiences and identities within as well as outside the university. This suggests that the traditional university design of separate departments focusing on specialized practices can potentially limit opportunities for the kind of connections across communities that are necessary for students to "finding ways of being in the world that can encompass multiple, conflicting perspectives in the course of addressing significant issues" (p. 275). Wenger suggests that "specialized settings" may need to be built in to an educational design.

I argue that writing centers are uniquely situated to fulfill that need. However, to accomplish that goal, writing centers will need to challenge their own traditional configuration of the one-to-one tutoring session and reifying practice in the form of writing center orthodoxies emerging from seminal scholarship in the field (North 1984, Bruffee 1984), which limit the potential for peer learning. The examples from my study provide evidence that writing centers are more than about "making better 
writers" (North, p. 69), and they are more than sites for initiating young writers into a particular kind of thinking and discourse (Bruffee 1984, "Peer Tutoring"). As noted in chapter one, others in the field of writing center studies are also calling for moving beyond the romanticized ideal of one-to-one peer tutoring. A design framework that supports the opening of new identities is one approach to invigorating that ideal as well as extending the reach of peer learning. In the next section, I summarize the design features and practices identified in my study and associate those features with Wenger's modes of belonging.

\section{Designing for Engagement, Imagination, and Alignment}

One of the ways writing centers directors can pay attention to the role of identity in the learning contexts they design is to examine the interaction within those contexts of the modes of belonging. Associating designs and practices with the work of engagement, imagination, and alignment can also help to identify opportunities for interaction with other communities—or what Wenger (1998) calls boundary work. In traditional educational designs, the importance of boundary work is often over-looked because classrooms generally function as closed systems and attention is focused on internalizing content that has been separated from authentic practice. Wenger argues that boundary work is an important dimension of learning because it allows communities to extend their reach and members to see the effects of their work in a larger context. It is also an important consideration for designers of learning communities like writing centers because coaches and students using the center 
negotiate multiple communities and memberships (p. 254). For the coaches and study team participants, course content was one of the structuring resources for learning along with their ability to establish meaningful social relationships. Traditional educational designs that emphasize an individualistic model of learning devalue the importance of social relationships. As Wenger (1998) notes, "Rather than mistrusting social relationships and interests, as traditional learning institutions often do, a learning community incorporates them as essential ingredients of learning in order to maximize the engagement of its members" (p. 272).

Because a learning community cannot be simply mandated into existence, designing for and creating a space for this type of "specialized setting" is a complex process. Drawing on the modes of belonging as design features is further complicated by the ways they can work together and against each other. Wenger argues, "Though engagement, imagination, and alignment are distinct modes of belonging, they are not mutually exclusive. A given community can be constituted by all three in various proportions, and the variety of these combinations results in communities with distinct qualities" (p.183). In this sense one mode of belonging can dominate, one mode may at times be in tension with another mode, and one mode of belonging can affect another. This means that designers must conduct ongoing investigations of these interactions, asking questions like what happens, for example, if imagination seems to dominate in this particular context? 
Wenger also warns of the limitations of engagement, imagination, and alignment. For example, to help explore the question above, it is necessary to consider that imagination can involve stereotypes, that engagement can be narrow, and that alignment can be blind and disempowering (p. 181). Reflective designers can work against these limitations by bringing them out in the open and a part of on-going discussion and redesign.

As design features, the modes of belonging place the emphasis on "the social infrastructures that foster learning" (p. 225). As I noted in the previous chapter, the findings of my study identified key features of the Michigan Tech Writing Center's design infrastructure that were especially important to creating and supporting a dynamic learning community. Some of these features were designed for and others were the result of the enaction of the designs in practice, which points to the importance of designers paying attention to the planned and the emergent aspect of a learning community. For example, coaches began looking for and creating informal ways to come together and discuss team activities and develop resources for learning. Support for this practice was then incorporated into the design of both the staff education course and the Center schedule. Critical features of the Center's design included:

- Multiple forms of participation

- Opportunities to engage in authentic practice

- Interaction of newcomers and old-timers 
- Legitimate role in decision-making

- Community building

- Open communication

Each of these features is simultaneously part of all three modes of belonging. For example, giving coaches a legitimate role in the Center's decision-making process deepened engagement and alignment with the Center's mission. Being part of the decision-making process also allowed coaches to imagine what running a writing center is like. In the next section, I highlight certain aspects of each mode.

\section{Designing for Engagement}

As noted above, social relationships are a key to engagement in a learning community. In traditional classroom settings working from an individualistic model of learning, students are generally viewed as learning the same things. Wenger (1998) explains that members of a learning community, on the other hand, contribute to the negotiation of meaning and development of a shared practice "in a variety of independent ways that become material for building an identity" (p. 271). Newcomers need to feel they are contributing even though full-participation is not expected at the onset. Instead, peripheral participation allows newcomers to contribute to and learn the practices of a community as they engage in its practices and interact with other members of the community. At the same time, newcomers' peripheral view of a community of practice can provide new insights and learning opportunities for both newcomers and old-timers. 
This understanding of engagement is significant for writing centers, particularly in the area of how staff education courses and programs are designed. Many writing centers incorporate engagement in actual practice into the training of newcomers. The question becomes to what extent meaning and practice is reified as part of training and how much is negotiated through sustained mutual engagement. Wenger suggests that the difference between training and education is that "training aims to create an inbound trajectory targeted at competence in a specific practice, [and] education must strive to open new dimensions for the negotiation of the self" ( $p$. 263). He describes purely extractive training as "schemes that 'extract' requirements, descriptions, artifacts, and other elements out of practice, transform them into institutional artifacts (courses, manuals, procedures, and the like), and then redeploy them in reified form." In contrast, integrative training "focuses on practice and seeks points of 'leverage' at which design can support learning" (p. 249). In the Michigan Tech Writing Center, this meant on-going targeted group discussion of the study team program. On a weekly basis, coaches and staff examined practice and developed new approaches in staff education sessions. Experienced coaches and new coaches worked together, which is often not the case in some writing center tutor training models where newcomers take an initial training course and then take part in less frequent full-staff meetings.

For writing centers, this suggests that supporting the work of engagement involves integrating rather than isolating newcomers from legitimate access to practice 
and more experienced coaches. This not only provides newcomers with important forms of participation but also allows for new ideas and approaches to refresh existing practices. Opportunities for coaches to interact with each other should be offered in both formal and informal configurations. For example, as part of the design, newcomers and old-timers can work together on projects, observe each other's sessions, present together at conferences. Time, space, and the communicative technologies to support these interactions must also be part of the design.

Opportunities for informal interactions can emerge from designs that configure spaces where coaches can gather between sessions, or use the writing center space after hours for other activities, such as a holding a poetry reading or campus event planning session. Accountability is also a part of engagement, and opportunities for exercising judgment, making decisions, and problem-solving are also important for newcomers and old-timers. In the Michigan Tech Writing Center, coaches were given a number of responsibilities, including planning team sessions, tracking attendance, and addressing team issues.

Accountability and responsibility cannot foster engagement unless designs are also attentive to the balance between reification and participation. Making tacit understandings of policies, procedures, decision-making practices, and learning models explicit and open to on-going discussion is another important aspect of engagement. While newcomers who are often anxious to "do the right thing" may benefit from the sense of the community coherence and guidance that prescribed 
practices offer, too much emphasis without an explicit understanding of the learning principles informing that practice can lead to rigid interpretations in practice. In the beginning semesters of the study team program, coaches struggled with utilizing the group process forms, which were intended to be a reflective and goal setting tool for the teams to complete after each session. "Filling out the form" became perfunctory with little value attached to it by coaches and team members. Discussing the benefits and limitations of the practice during the staff education meetings as well as soliciting on-going feedback from the coaches and participants was an important part of rethinking its use.

Wenger (1998) notes that "design can invite allegiance or be satisfied with mere compliance; it can thrive on participation or impose itself through nonparticipation" (p. 235). Reified policies and procedures that prompt statements from peer tutors such as "we never write on a student's paper," or "we don't proofread," or "we make the student do all the work" can produce unintended consequences and limit the sort of mindful and creative engagement that practitioners can bring to a community. Listening for the interaction of the planned and the emergent should be an ongoing process of design. As applied to engagement, Wenger describes that interaction as "situated improvisation within a regime of accountability" (p. 240).

Making community-building activities a part of the design is also important to supporting engagement. Traditional educational settings are good at separating learners by experience level (newcomers and old-timers) and by specialization 
(majors/disciplines). In writing centers, fragmentation of the community can happen if the center has one site or several, if it focuses on one joint enterprise such as face-toface sessions over a piece of writing, or several, such as online consulting, writing center courses, fellows programs, multimedia consulting, and language learning support. In many ways, staff education and development is a much about community building as training. In the Michigan Tech Writing Center, taking on a large program like the World Cultures study teams brought community building to the forefront of not only the team design, but also for the Center. The joint enterprise of leading teams brought coaches together in new configurations that were unlike their one-to-one sessions. In some ways, the team approach to learning made the benefits of community building more visible. Working one-to-one with an individual student and her text does not invite community building in the same way, although it is still important. Coaching the teams was a clearly defined joint enterprise where working together to achieve goals was both efficient and productive. Applying the same level of communal resource development and social interactions over the joint enterprise of one-to-one coaching can invigorate that practice.

Wenger (1998) argues that a trade-off of engagement is that it can be narrow, and "competence can become so transparent, locally ingrained, and socially efficacious that it becomes insular: nothing else, no other viewpoint, can even register..." (p.175). At the level of the field of writing center studies, I think this can be seen in those arguments that revel in the "marginalized status" or what I would call 
an "identity of marginalization" of writing centers within academic institutions (Kinkead 1996). Writing centers that view themselves as outsiders within their academic institutions restrict their ability to remain relevant to the communities they serve. As Wenger suggests, "in this way, a community of practice can become an obstacle to learning by entrapping us in its very power to sustain our identity" (p. 175). At the level of the study teams, an identity of "us versus them" or the teams versus the course was a source of tension and obstacle to engagement. Designers need to help coaches address issues like these through infrastructures that allow them to imagine other perspectives in productive ways. In the Michigan Tech Writing Center, faculty teaching the course were invited to the Center for a presentation about the program by the coaches along with time to socialize after the program. This practice not only served as a way of deepening engagement but also brought new viewpoints into the Center.

\section{Designing for Imagination}

Wenger explains that when imagination is combined with engagement in practice, it brings a reflective dimension to the practice (p. 217). It's a way to imagine practices from a different viewpoint and adopt another perspective, and thereby address the potential for engagement to become narrow. He emphasizes that for imagination to be more than simple fantasy, it has to "have effects beyond itself so we learn from it by bringing it back into a form of engagement" (p. 217). In the example above, through the interaction of the coaches and instructors, each community was 
able to imagine a dimension of the other, and bring back a new understanding to their practice. One instructor noted that understanding more about the teams made him think about the teams when designing his study worksheets.

The coaches' interactions with each other also are an important part of facilitating the work of imagination. The differing perspectives and experiences they possess are part of who they are and what they imagine about each other lives. Coaches who had taken the course shared their experiences with other coaches who could then better imagine and reflect on student responses to the design of the course. Within the teams, coaches drew on the work of imagination to deepen engagement and interaction with the material of the course. They introduced playfulness through games or activities that asked students to imagine another culture as well as learn facts.

Their differences are also a part of how the Center imagines itself as demonstrated by the reports of the Center's diversity on its website. An explicit articulation of the values of the center, including the value for differing perspectives, was important to incorporating the work of imagination into the community.

For writing centers, this also suggests that designs should include activities for rethinking practices, such as creating scenarios and role-playing during staff education sessions. Attending conferences and gaining new perspectives on how other centers operate requires the work of imagination. Newcomers are often shocked at how different other centers are from their own in part because their ability to imagine is still very locally ingrained. As newcomers are given more opportunities to view their 
own practice from different vantage points - a conference, another learning center on campus, an instructor, a scholarly article - they can imagine new practices or come to understand and connect more directly with existing ones. To fully capture the effects of imagination, design also must incorporate opportunities to share experiences beyond local practice, like attending a conference, participating in meetings with instructors, and other administrators and groups within the institution.

In terms of a trajectory of learning, imagination has a past as well as a future. When study team participants want to become coaches, they are imagining what that would be like from their own experiences. It is also important for them to have a sense of the history of the center so they can imagine how their experiences will contribute to that shared history. Infrastructure and design can mark the histories of past coaches within the Center through resources, collections of presentations, and scholarly work. One new study team coach noted that she felt connected to former coaches through the resources they created for the teams. In this sense, imagination is not only an individual process but is "anchored in social interactions and communal experiences" (p. 178).

The trade-off of imagination, according to Wenger (1998) is that it can "overlook the finer texture of practice" and rely on overgeneralizations and stereotypes (177). This suggests that when writing center handbooks characterize certain groups of students a certain way — the resistant writer, the basic writer, the second-language writer, the writer who plagiarizes - there is an inherent danger of 
overgeneralizing and stereotyping that can produce negative effects. In a similar way, mantras such as "better writers, not better writing" (North, 1984) can fuel the imagination in unintended ways. Directors should ask themselves, how does a peer tutor imagine a "better writer" and how does that image influence practice? Designers can work against the dangers of overgeneralizing and stereotyping by bringing them out into the open and challenging their assumptions.

\section{Designing for Alignment}

For educational designs to be effective, Wenger (1998) argues they must "engage learning communities in activities that have consequences beyond their boundaries, so that students may learn what it takes to become effective in the world" (p. 274). He further explains that "toward this end, they must have first-hand experience of what it takes to accomplish something on a larger scale" (p. 273). This is the work of alignment, and working in a writing center can provide the type of experience that allows peer tutors to view themselves as part of something larger.

Providing opportunities for peer tutors to interact with other communities or boundary work is an example of alignment. When all the Michigan Tech Learning Centers come together for the annual banquet, coaches see themselves as valuable members of a larger community. Similarly, giving coaches opportunities to represent the Center at conferences or campus events also broadens the effects of their practice. 
Supporting the work of alignment involves sharing successes by involving coaches in the reporting process, data collection, and decision-making. Alignment invites allegiance to the cause of the writing center. In the Michigan Tech Writing Center, the emphasis on the core values of the Center is one example of supporting the work of alignment. They are not simply reifications in a manual but expectations of practice. As noted in chapter four, Rebecca turned her alignment with the Center's core values into action by participating in workshops on listening designed to counter backlash toward international teaching assistants and in the classroom where she would advocate for the importance of diversity with students in her major field of study.

In some ways, designing for issues of alignment can be the most challenging and perhaps the most important of the modes of belonging. As a form of identity, alignment implies multiple memberships, which Wenger (1998) argues requires the work of reconciliation. In the examples above, alignment with the expectations of one community can be in conflict with the expectations of other communities to which coaches belong. To foster learning, Wenger notes that communities must push their boundaries but doing so expands the possibility for a clash of expectations and perspectives. As Wenger suggests, "the work of reconciliation may be the most significant challenge faced by learners who move from one community of practice to another" (p.160). While the Michigan Tech Writing Center has high expectations for its programs, it incorporates a flexible design that provides opportunities for those 
expectations to not be a prescriptive process of blind allegiance, but a process where coaches are a legitimate part of development of best practices. The opportunity to negotiate and coordinate multiple perspectives in practice provides an invaluable learning experience for coaches as they address issues of alignment in other communities.

Issues of alignment and reconciliation are important areas of attention for designers of learning communities, but they can be overlooked when a prescriptive infrastructure renders them invisible. Wenger (1998) argues that the trade-off for alignment is that it can be "blind and disempowering" (p. 181). In traditional models of learning, students' experiences and memberships in other communities for example, families or religions, and the work they must do to reconcile issues of alignment between those memberships and the classroom is not a part of the learning curriculum. Instead of learning to reconcile identities with new perspectives, they are asked to abandon or ignore them. As a closed system, traditional classroom learning lacks the advantages of boundary work.

When a learning community makes room for and pays attention to boundary crossings, members not only gain experience in negotiating multiple memberships, but also the community itself can be invigorated by new practices, identify areas of "miscommunication,. . .explain unusual events,... and unexpected interpretations" (p.254). For writing centers, this type of work is important to establishing a sustainable learning community. 
As noted earlier in this chapter the degree to which communities are constituted by engagement, imagination, and alignment serves to define them. In part through its development of the study teams and the social theory of learning that informed it, the Center transformed itself. Reflective practice is a defining characteristic of the Center, which Wenger (1998) argues is a result of linking engagement and imagination because it "combines the ability both to engage and to distance" (p.217). Through the joint enterprise of the study team program, the combination of imagination and alignment can be seen as the coaches learn to direct their activities with others in the service of larger goals. Designing for multiple forms of participation in the program and interactions with each other are important to facilitating this combination. Wenger argues that "multimembership is a critical source of learning because it forces an alignment of perspectives in negotiation of an engaged identity" (p.218). Coaching the study teams made visible tensions and discontinuities among the learning theories informing the course and the goals of teams, as well as other overlapping perspectives and issues. It is clear that the combination of engagement and alignment is critical to helping coaches negotiate the work of reconciliation in productive ways.

Addressing these issues for writing center directors means bringing them out in the open and exploring their relationships including the tensions among them. Designs need to be opportunistic and flexible and consider, for example, the ways an emphasis on risk-taking and play (imagination) may conflict with expectations and standards of 
practice (alignment), how at different times during the semester a different combination of the modes is necessary; for example, providing more emphasis on engagement for newcomers. Paying attention to the work of engagement, imagination, and alignment means creating a broader educational vision. Rather than a model of individualized help, writing centers should be viewed as an integral site in the learning ecology. As a "specialized setting" open to boundary crossings and the negotiation of multiple perspective, writing centers can be leaders in defining learning within their institutions. 


\section{References}

Arum, R. \& Roksa, J. (2011). Academically adrift: Limited learning on college campuses. Chicago, IL: The University of Chicago Press.

Babcock, R. and Thonus, T. (2012). Researching the writing center: Towards evidence-based practice. New York, NY: Peter Lang.

Barnett, R. \& Blumer, J. (Eds.) (2001). The process of tutoring: Connecting theory and practice. In The Allyn and Bacon guide to writing center theory and practice (pp. 203-205). Boston, MA: Allyn and Bacon.

Barton, D. (1994). An introduction to the ecology of written language. Oxford, UK: Blackwell Publishing.

Barton, D. \& Hamilton, M. (1998). Local literacies: Reading and writing in one community. New York, NY: Routledge.

Boquet, E. (1999). Our little secret: A history of writing centers pre- to post-open admissions. College Composition and Communication, 50, 463-82.

Burnham, C. (2001). Expressive pedagogy: Practice/theory, theory/practice. In G. Tate, A. Rupiper, \& K. Schick (Eds.), A Guide to Composition Pedagogies. New York, NY: Oxford University Press, (pp. 19-35).

Brandt, D. (2001). Literacy in American lives. New York, NY: Cambridge University Press.

Brooks, J. (1991). Minimalist tutoring: Making the student do all the work. Writing Lab Newsletter, 15(6), 1-4. 
Bruffee, K. (1978). The Brooklyn plan: Attaining intellectual growth through peergroup tutoring. Liberal Education, 64, 447-468.

Bruffee, K. (1984). Collaborative learning and the "conversation of mankind." College English, 46(7), 635-652.

Bruffee K. (1984). Peer tutoring and the "conversation of mankind." In R. Barnett \& J. Blumer (Eds.), The Allyn and Bacon guide to writing center theory and practice (pp. 206-218). Boston, MA: Allyn and Bacon.

Bruffee, K. (1999). Collaborative learning: Higher education, interdependence, and the authority of knowledge (2nd ed.). Baltimore, MD: Johns Hopkins University Press.

Carino, P. (1995). Theorizing the writing center: An uneasy task. In R. Barnett \& J. Blumer (Eds.), The Allyn and Bacon guide to writing center theory and practice (pp. 124-138). Boston, MA: Allyn and Bacon.

Council for Aid to Education. (n.d.) CLA+ overview. Retrieved from http://cae.org/performance-assessment/category/cla-overview/

Cooper, M. (1986). The ecology of writing. In M. Cooper \& M. Holzman (Eds.), Writing as social action. Portsmouth, NH: Boynton/Cook.

Cooper, M. (2001). Forward: The truth is out there. In C. Weisser \& S. Dobrin (Eds.) Ecocomposition: Theoretical and pedagogical approaches. New York, NY: State University of New York Press. 
Fleckenstein, K., Spinuzzi, C., Rickley, R., Papper, C. (2008). The importance of harmony: An ecological metaphor for writing research. College Composition and Communication, 60(2), 388-419.

Eodice, M. (2008). An interview with Kenneth A. Bruffee. The Writing Center Journal, 28(2), 33-41.

Emerson, R., Fretz, R. \& Shaw, L. (1995). Writing ethnographic fieldnotes. Chicago, IL: The University of Chicago Press.

Gee, J. (1990). Social Linguistics and literacies: Ideology in discourses (2nd ed.). Bristol, PA: Taylor \& Francis.

Gee, J. (2003). What video games have to teach us about learning and literacy. New York, NY: Palgrave Macmillan.

Geller, A., Eodice, E., Condon, F., Carroll, M. \& Boquet, E. (2007). The everyday writing center: A community of practice. Logan, UT: Utah State University Press.

Gillespie, P. \& Lerner, Neal. (2000). The Allyn and Bacon guide to peer tutoring (2nd edition). New York, NY: Longman.

Graff, H. (2011). Literacy myths, legacies \& lessons: New studies on literacy. New Brunswick, NJ: Transaction Publishers.

Grimm, N.M. (1999). Good intentions: Writing center work for postmodern times. Portsmouth, NH: Heinemann. 
Grimm, N. M. (2011). Retheorizing writing center work to transform a system of advantage based on race. In L. Greenfield \& K. Rowan (Eds.), Writing centers and the new racism (pp. 75-100). Logan, Utah: Utah State University Press.

Hall, E. \& Hughes, B. (2011). Preparing faculty, professionalizing fellows: Keys to success with undergraduate writing fellows in WAC. The WAC Journal, 22, $23-40$.

Hughes, B., Gillespie, P., Kail, H. (2010). What they take with them: Findings from the peer writing tutor alumni research project. The Writing Center Journal, $30(2), 12-46$.

Harris, M. (1986). Teaching one-to-one: The writing conference. Urbana, IL: National Council of Teachers of English.

Harris, M. (1988). Concept of a writing center. International Writing Centers Association. Retrieved from http://writingcenters.org/resources/writing-centerconcept/

Harris, M. (1990). What's up and what's in: Trends and traditions in writing centers. The Writing Center Journal, 11(1) 15-25.

Harris, M. (2002). Writing center administration: Making local, institutional knowledge in our writing centers. In P. Gillespie, A. Gillam, L.F. Brown, \& Byron Stay (Eds.), Writing center research: Extending the conversation. (pp. 75-89). Mahwah, NJ: Lawrence Erlbaum Associates. 
Hawk, B. (2007). A counter-history of composition: Toward methodologies of complexity. Pittsburgh, PA: University of Pittsburgh Press.

Heath, S. (1983). Ways with words: Language, life and work in communities and classrooms. New York NY: Cambridge University Press.

Heath, S. \& Street, B. (2008). Ethnography: Approaches to language and literacy research. New York, NY: Teachers College Press.

Hobson, E. (1992). Maintaining our balance: Walking the tightrope of competing epistemologies. In R. Barnett \& J. Blumer (Eds.), The Allyn and Bacon guide to writing center theory and practice (pp. 100-109). Boston, MA: Allyn and Bacon.

Kinkead, J. (1996). The national writing centers association as mooring: A personal history of the first decade. In R. Barnett \& J. Blumer (Eds.), The Allyn and Bacon guide to writing center theory and practice (pp. 29-40). Boston, MA: Allyn and Bacon.

Kuh G., Douglas, K., Lund, J., \& Gyurmek-Ramin, J. (1994). Student learning outside the classroom: Transcending artificial boundaries. Washington, D.C.: The George Washington University, Graduate School of Education and Human Development.

Lave, J. and Wenger, E. (1991) Situated learning: Legitimate peripheral participation. New York, NY: Cambridge University Press. 
146

Lundsford, A. \& Ede, L. (2011). Reflections on contemporary currents in writing center work. The Writing Center Journal, 31(1), (pp. 11-24).

Maturana, H. \& Varela, F. (1987). The tree of knowledge: The biological roots of human understanding (rev. ed.). Boston, MA: Shambhala.

MTU Writing Center. (2001). Coaching World Cultures study teams. Houghton, MI: MTU Writing Center.

Michigan Tech Multiliteracies Center (2013). Mission. MTMC. Retrieved from http:/www.mtu.edu/humanities/resources/mtmc/

New London Group. (2000). A pedgogy of multiliteracies designing social futures. In B. Cope \& M. Kalantzis (Eds.), Multiliteracies: Literacy learning and the design of social futures. New York NY: Routledge.

North, S. (1984). The idea of a writing center. In R. Barnett \& J. Blumer (Eds.), The Allyn and Bacon guide to writing center theory and practice (pp. 63-78). Boston, MA: Allyn and Bacon.

Ryan, L. \& Zimmerelli, L. (2010). The Bedford guide for writing tutors (5th ed.). Boston, MA: Bedford/St. Martin’s.

Sternglass, M. (1997). Time to know them: A longitudinal study of writing and learning at the college level. Mahwah, NJ: Lawrence Erlbaum Associates.

Street, B. (1984). Literacy in theory and practice. Cambridge, UK: Cambridge University Press. 
Street, B. (1995). Social literacies: Critical approaches to literacy in development, ethnography and education. New York, NY: Longman.

Street, B. (2001). Introduction. In B. Street (Ed.), Literacy and development: Ethnographic perspectives. New York, NY: Routlege.

Syverson, M. (1999). The wealth of reality: An ecology of composition. Carbondale, IL: Southern Illinois University.

Trimbur, J. (1989). Consensus and difference in collaborative learning. In Shannon, P. (Ed.), Becoming political: Readings and writings in the politics of literacy education (pp. 208-222). Portsmouth, NH: Heinemann.

Welch, N. (1993). From silence to noise: The writing center as critical exile. The Writing Center Journal, 3-15.

Wenger, E. (1998) Communities of practice: Learning, meaning, and identity. New York, NY: Cambridge University Press. 